\title{
OPEN Long-term capture and handling effects on body condition, reproduction and survival in a semi-aquatic mammal
}

\begin{abstract}
Rasmus M. Mortensen ${ }^{\varpi}$ \& Frank Rosell
In long-term individual-based field studies, several parameters need to be assessed repeatedly to fully understand the potential fitness effects on individuals. Often studies only evaluate capture stress that appears in the immediate weeks or breeding season and even long-term studies fail to evaluate the long-term effects of their capture procedures. We investigated effects of long-term repeated capture and handling of individuals in a large semi-aquatic rodent using more than 20 years of monitoring data from a beaver population in Norway. To investigate the effects, we corrected for ecological factors and analysed the importance of total capture and handling events, years of monitoring and deployment of telemetry devices on measures related to body condition, reproduction and survival of individual beavers. Body mass of dominant individuals decreased considerably with number of capture events (107 g per capture), but we found no statistically clear short or long-term effects of capture and handling on survival or other body condition indices. Annual litter size decreased with increasing number of captures among older individuals. Number of captures furthermore negatively affected reproduction in the beginning of the monitoring, but the effect decreased over the years, indicating habituation to repeated capture and handling. By assessing potential impacts on several fitnessrelated parameters at multiple times, we can secure the welfare of wild animal populations when planning and executing future conservation studies as well as ensure ecologically reliable research data.
\end{abstract}

Studying individuals of a population repeatedly over longer time periods yields substantial scientific insights on age-related changes in various vital rates such as growth ${ }^{1}$, reproductive performance ${ }^{2}$ and survival ${ }^{3}$, but also enables possibilities to connect events and changes at one life-history stage to those of another ${ }^{4}$.

Capture and handling events are expected to induce immediate physiological and behavioural adjustments for the individual to cope with the disturbance, which may result in an intense stress response that can have physical, physiological and behavioural consequences ${ }^{5,6}$. These potential changes in behavioural patterns can affect body condition as well as vital rates and may consequently negatively influence mating success and fitness ${ }^{7-9}$.

To evaluate these potential capture and handling effects, researchers often focus on the immediate harm that could be caused, such as mortalities and physical injuries. Capture and handling methods are often considered efficient as long as the animal survives through the process without noticeable injuries ${ }^{10}$. However, animals often hide symptoms that make them appear vulnerable ${ }^{11}$. Mortality rates and physical injuries at time of capture are not sufficient to successfully assess capture and handling procedures, as the full impact cannot be determined without also evaluating physical, behavioural and physiological effects at multiple times on a long-term scale ${ }^{12,13}$.

When evaluating the more indirect effects of capture and handling in a wide range of species, researchers have, among other things, analysed changes in various body condition indices ${ }^{9,14-16}$, reproductive performance ${ }^{8,17-22}$ and mortality ${ }^{5,10,23-29}$. Most studies only evaluate capture and handling effects using a limited number of parameters associated to, for example, physiology or reproduction, and seldom several categories ${ }^{30}$. However, we might not be able to detect changes in some parameters ${ }^{22}$, or parameters might not be affected despite the level of stress ${ }^{31}$ and animals may habituate to cope with stress ${ }^{32}$. Often effects are only evaluated on a time scale from a couple of weeks to a year after capture, which may relate to limitations of the measured parameters and constraints related to the framework of the project ${ }^{33}$. Even long-term studies that last several seasons are mostly evaluated within each season $^{30}$, although capture and handling may affect individuals at later life stages and across generations ${ }^{18,34}$. 
To determine the full impact of repeated capture and handling, we need more evidence-based knowledge on physical, behavioural and physiological effects at both short and longer time-scales to understand how capture and handling procedures might affect body condition as well as vital rates that consequently may negatively influence reproductive performance and survival ${ }^{8,9}$.

We use Eurasian beavers (Castor fiber) as a model species to study long-term effects of repeated capture and handling in a highly territorial, semi-aquatic mammal. Beavers (including C. canadensis) have been intensively studied describing, among other things, reproduction ${ }^{35-37}$, territorial communication ${ }^{38-41}$, resource and habitat use $^{42-45}$ and time-budgets ${ }^{46-48}$. However, effects of capturing and handling individuals, as well as deploying telemetry devices, which have taken place in several of these research projects, have not been investigated besides short-term effects of tagging ${ }^{16,49}$. One would expect these procedures to induce stress responses that may affect short term body condition measures (fat storage in the tail ${ }^{37}$ ) and behaviour of the beavers. However, these behavioural changes may also affect body condition in the long term and potentially affect the whole population, negatively influencing mating success and survival at several life-history stages and in coming generations ${ }^{4}$.

In our study, we aim to investigate the effects of long-term capture, handling and tagging in a large semiaquatic rodent, using monitoring data of a beaver population in south-eastern Norway which has experienced repeated capture and handling events since 1997. To investigate the long-term effects, we corrected for ecological factors and analysed the importance of capture and handling events, years of monitoring and deployment of telemetry devices on measures related to body condition, reproduction and survival of individual beavers, all of which ultimately affect fitness of individuals.

\section{Results}

We made on average (mean \pm SD) $65.8 \pm 8.1$ annual captures (median $=63$ ). Kits were captured up to four times $($ mean $=1.1 \pm 1.1$, median $=1)$. Captured yearlings experienced up to five captures $($ mean $=1.9 \pm 1.4$, median $=2)$ and subadults up to seven captures (mean $=3.0 \pm 1.7$, median $=3$ ), including captures in previous life stages. Adult beavers were captured up to twenty-five times in their lifetime (mean $=5.1 \pm 2.3$, median $=4)$. Dominant adults experienced more captures than subordinates $\left(\right.$ mean $_{\text {dominant }}=6.3 \pm 2.5$, median ${ }_{\text {dominant }}=5$, mean $_{\text {subordinate }}=2.6 \pm 1.6$, median $\left._{\text {subordinate }}=2\right)$ and males and females were captured equally $\left(\operatorname{mean}_{\text {males }}=4.4 \pm 2.1\right.$, median $_{\text {males }}=3$, mean $_{\text {females }}=4.1 \pm 2.0$, median $_{\text {females }}=3$ ).

Body condition indices. We found no statistically clear effects of the number of capture and handling events, years of monitoring or from carrying telemetry devices on the variability of the tail fat index in our population. Tail fat index varied clearly with capture season and age among both young and adult individuals (Table 1). It increased clearly over time among individuals, resembling increase in body growth. Among adult individuals, tail fat index increased up to approximately eight years, after which it decreased (Fig. 1). Furthermore, we found statistically clear intra-annual variation in tail fat index among adults with tail fat clearly increasing between spring and autumn (Table 1, Fig. 1). No statistically clear differences were found among young males and females, but adult females had smaller tail fat index than males (Table 1).

We found a statistically clear negative effect of capture events on the body mass of dominant individuals, but found no statistically clear effects on other individuals, of years of monitoring, or from carrying telemetry devices (Table 2, Fig. 2). Body mass increased clearly within the year from spring to autumn and with increasing age up to approximately 10 years (Fig. 2). Young individuals from larger territories had smaller body weights than young individuals from smaller territories (Table 2, Fig. 2). As expected, dominant beavers had larger body mass than subordinates (Table 2, Fig. 2). We found no statistically clear differences between young males and females, but adult females were clearly bigger than males in spring and summer (Table 2, Fig. 2).

No statistically clear effects were found of either number of capture and handling events, years of monitoring or carrying telemetry devices on body length (Table 3). Body length increased clearly within the year from spring to autumn and with increasing age up to approximately 10 years (Fig. 3). Young individuals from larger territories were smaller than young individuals from smaller territories. We found no statistically clear differences in body size among sexes or social rank.

Reproduction. Between 1998 and 2018, we observed 65 dominant females, which produced 1-4 kits in reproducing years. They reproduced on average every $2.5 \pm 0.6$ years during the duration of their territory occupancy.

Number of capture and handling events and years of monitoring had statistically clear effects on both yearly reproduction and annual number of kits produced among females in our population (Table 4, Fig. 4). An increasing number of capture events seemed to have a negative effect in the early monitoring years on both yearly reproduction and annual number of offspring. However, this effect became less clear over the years of the monitoring program. Furthermore, we found a statistically clear negative effect of number of capture and handling events on annual number of offspring produced by older beavers (Table 4, Fig. 4). We found no statistically clear differences among the other investigated variables.

Survival. No statistically clear effects were found of number of capture and handling events, years of monitoring or carrying telemetry devices on annual survival (Table 5). Only social status, age and family group size had statistically clear effects on annual survival (Table 5). We found a clear increasing probability of annual survival with age for dominant individuals, whereas annual survival decreased with age for subordinates and with increasing family group size (Fig. 5).

We found no statistically clear effects of number of capture and handling events, years of monitoring or carrying telemetry devices on the probability of staying dominant in a territory the following year (Table 6). We found 


\begin{tabular}{|c|c|c|c|c|c|c|}
\hline Variables & Estimate & SE & LCI & UCI & $\mathbf{R}_{\text {marginal }}^{2}$ & $\mathbf{R}_{\text {conditional }}^{2}$ \\
\hline \multicolumn{7}{|l|}{ Young (kits and yearlings) } \\
\hline Intercept & 1.496 & 0.089 & 1.322 & 1.670 & 0.56 & 0.73 \\
\hline Captures & 0.001 & 0.014 & -0.026 & 0.028 & & \\
\hline Years of monitoring & 0.002 & 0.004 & -0.006 & 0.010 & & \\
\hline Sex (male) & -0.018 & 0.037 & -0.090 & 0.054 & & \\
\hline Age & 1.051 & 0.050 & 0.952 & 1.150 & & \\
\hline Season (summer) & 0.486 & 0.061 & 0.366 & 0.606 & & \\
\hline Season (autumn) & 0.784 & 0.068 & 0.651 & 0.917 & & \\
\hline Log (territory size) & -0.079 & 0.051 & -0.179 & 0.021 & & \\
\hline Family group size & -0.003 & 0.008 & -0.019 & 0.013 & & \\
\hline \multicolumn{7}{|l|}{ Adults (2+years) } \\
\hline Intercept & 3.641 & 0.107 & 3.431 & 3.852 & 0.12 & 0.48 \\
\hline Captures & -0.005 & 0.006 & -0.017 & 0.007 & & \\
\hline Years of monitoring & 0.000 & 0.002 & -0.004 & 0.003 & & \\
\hline Carried telemetry device (yes) & -0.006 & 0.021 & -0.047 & 0.034 & & \\
\hline Sex (male) & 0.131 & 0.038 & 0.055 & 0.206 & & \\
\hline Age & 0.100 & 0.022 & 0.058 & 0.142 & & \\
\hline $\mathrm{Age}^{2}$ & -0.006 & 0.001 & -0.008 & -0.004 & & \\
\hline Social status (subordinate) & -0.145 & 0.079 & -0.299 & 0.009 & & \\
\hline Origin (resident) & -0.001 & 0.016 & -0.033 & 0.031 & & \\
\hline Season (summer) & 0.022 & 0.032 & -0.040 & 0.084 & & \\
\hline Season (autumn) & 0.131 & 0.052 & 0.029 & 0.233 & & \\
\hline Log (territory size) & -0.008 & 0.018 & -0.043 & 0.028 & & \\
\hline Family group size & 0.001 & 0.004 & -0.006 & 0.008 & & \\
\hline Captures: social status (subordinate) & 0.000 & 0.003 & -0.006 & 0.006 & & \\
\hline Season (summer): sex (male) & -0.011 & 0.035 & -0.080 & 0.059 & & \\
\hline Season (autumn): sex (male) & -0.061 & 0.074 & -0.206 & 0.083 & & \\
\hline Social status (subordinate): age & 0.018 & 0.011 & -0.005 & 0.040 & & \\
\hline
\end{tabular}

Table 1. Effect size ( $\beta$ ), standard error (SE), lower (LCI) and upper (UCI) 95\% confidence interval of explanatory variables for the analysis of tail fat index in a Eurasian beaver population in south-eastern Norway between 1998 and $2018\left(\mathrm{n}_{\text {young }}=333, \mathrm{n}_{\text {adults }}=828\right)$. Beaver ID, capture year and river were included as random effects. We performed model averaging of best models $(\triangle \mathrm{AICc}<4)$ to estimate the effect size of each variable. Informative parameters are given in bold. Reference level of sex: female. Reference level of season: spring. Reference level of carried telemetry device: no. Reference level of social status: dominant. Reference level of origin: immigrant.

a decreasing probability of staying dominant with increasing age and an increasing probability with increasing family group size (Table 6, Fig. 6). No statistically clear differences were found for other investigated variables.

\section{Discussion}

By evaluating at multiple points in time on a long-term scale, how more than twenty years of repeated capture and handling of individuals in a beaver population affect body condition, reproductive performance and survival, we thoroughly investigate capture and handling effects on important vital rates that ultimately influence fitness of the animals ${ }^{4}$. We found statistically clear effects of repeated capture and handling on body mass of dominant individuals, but found no statistically clear effects of repeated capture and handling on any of the other body condition indices or annual survival probability. However, we observed statistically clear changes through the years in reproductive performance of dominant females, clarifying the importance of investigating several parameter categories when evaluating the consequences of capturing and handling individual animals ${ }^{9,12,13}$. To fully understand fitness effects of capture procedures, one should repeatedly evaluate capture and handling effects at several points in times. Often studies only evaluate capture stress that appears in the immediate days, weeks or the following breeding season after handling ${ }^{30}$. Even long-term studies that investigate capture and handling effects for several years sometimes fail to evaluate long-term effects of their procedures, since they only evaluate short-term effects within each year and season ${ }^{50-52}$. But as we show, capture effects might also have longer-term consequences for individuals, indicating the need for repeated evaluations of condition and fitness. However, this may prove unviable because of limited timeframes or other constraints within the framework of the project that may challenge such long-term continuity ${ }^{33}$.

Body condition. Body condition indices resemble snapshots of the physiological state of an animal, indicating e.g. past foraging success or ability to cope with environmental pressures ${ }^{14,53}$, which may impact other life- 

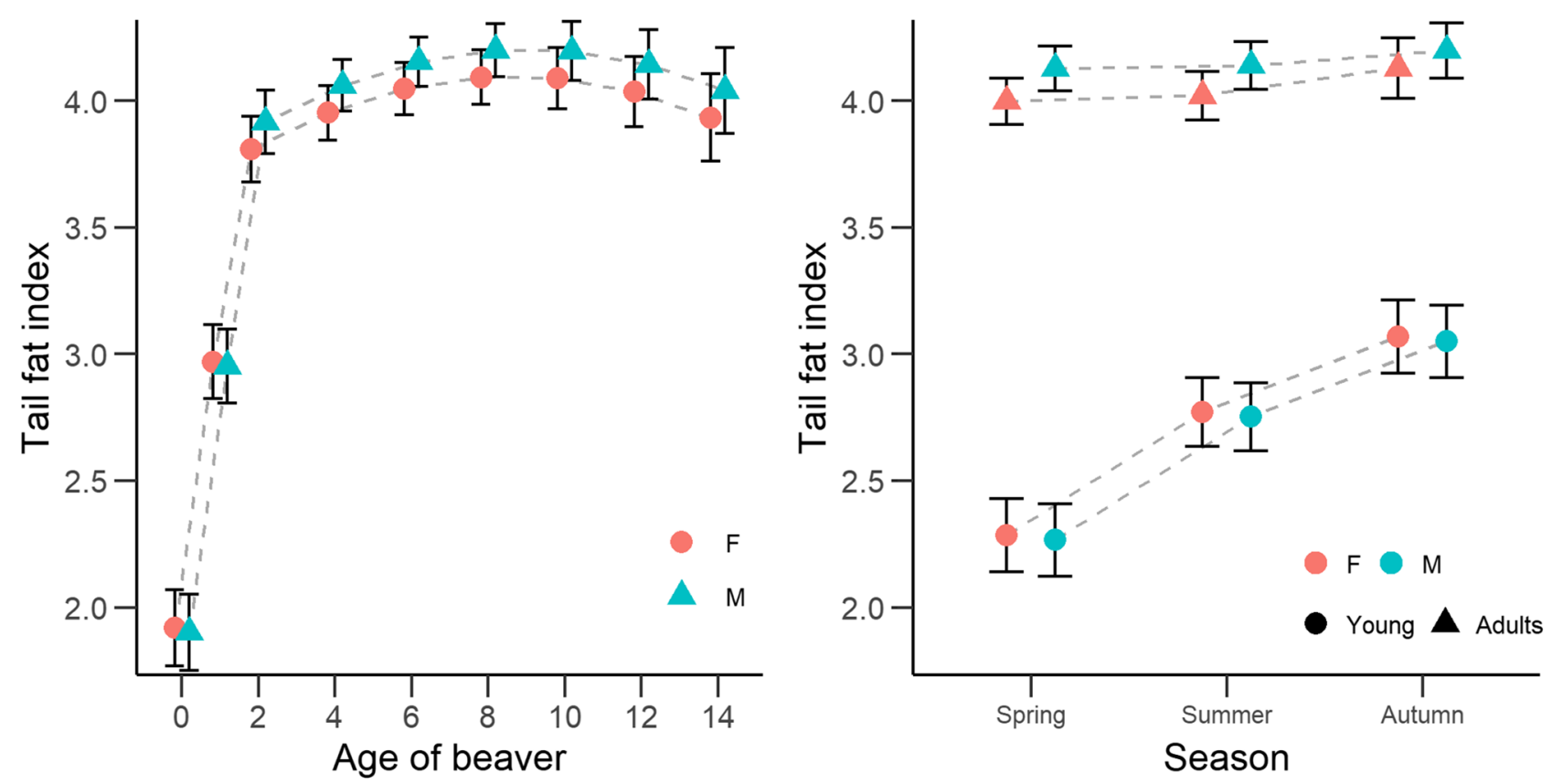

Figure 1. The predicted relationship $\pm 95 \%$ confidence interval between age, sex and tail fat index (a) and age, sex, season and tail fat index (b) in a Eurasian beaver population in south-eastern Norway between 1998 and 2018.

history stages, future reproductive success, and ultimately evolutionary fitness ${ }^{54,55}$. We therefore expected to find variations in size and mass in our population related to number of capture and handling events experienced by each individual, as well as a development over the years of the Norwegian Beaver Project (NBP) as an indication of experienced long-term stress. While several studies have observed negative effects of repeated captures on body condition, body mass and length, only few studies have looked at long-term effects ${ }^{30}$. In long-term studies, up to 21 years, bears that experienced more recaptures had a poorer age-specific body condition' ${ }^{9}$. Similar negative effects have been found among rodents live-trapped over two years ${ }^{15}$. Neither tail fat index nor body length were affected short or long-term by repeated captures and handling in our population. However, we did find a clear decrease in body mass with increasing capture and handling events among dominant individuals. Other studies in beavers have observed greater weight loss and decrease in tail area over the following winter when being equipped with transmitters ${ }^{16}$. We might expect more short-term effects within days post-capture related to the individuals staying more in lodge and being less active as an immediate response to the capture event ${ }^{49}$.

Tail fat index, body mass and body size increased considerably between life stages of beavers, reflecting their growth rate. Furthermore, they increased over the year, especially among young individuals, which increase relatively more in mass and size. But also adults showed seasonal variations similar with findings in other populations ${ }^{56}$.

Females in the reproductive age generally had smaller tail size and higher body mass in spring and summer when reproduction occurs, indicating differentiation in allocation of time and energy among sexes. Comparing time-budgets of males and females, no differences were found ${ }^{46}$, which is expected in monogamous animals ${ }^{57}$. Males allocated more time to travel which might indicate an increased patrolling effort or search for food items, whereas females might spend more time on parenting activities, which our results support.

Only body mass was greater among dominant individuals, indicating this as an important feature of social status $^{58}$, whereas tail size and body length might be more socially stable to maximize fitness of individuals ${ }^{37}$. Social rank is highly shaped by agonistic interactions between individuals ${ }^{59}$, where body size can be an important factor $^{60}$. However, the social hierarchy may also be influenced by affiliative interactions ${ }^{61}$. In beavers only the dominating pair breed. Also among high ranked individuals in other social rodents have body size correlated with greater reproductive success ${ }^{62}$. In our population, body mass decreased among dominant individuals with increasing number of capture and handling events. Dominants have a higher energy expenditure due to increased territorial defence and reproduction ${ }^{36,37,41}$, which may suggest they might be more susceptible to capture stress ${ }^{7,60}$.

Young individuals of larger territories were found to have lower body mass and smaller body length, which might be a result of parents spending more time on patrolling than parenting ${ }^{47}$. Generally, costs of defending a territory are positively correlated with territory size ${ }^{63}$ and young individuals might suffer as a consequence. Larger territories may have fewer quality food resources and might be larger to provide adequate resource availability ${ }^{64-66}$. However, we found no effect of territory size among adults suggesting that territorial behaviour in our population, to a lesser degree, follows the availability of food resources ${ }^{67}$. 


\begin{tabular}{|c|c|c|c|c|c|c|}
\hline Variables & Estimate & SE & LCI & UCI & $\mathbf{R}_{\text {marginal }}^{2}$ & $\mathbf{R}_{\text {conditional }}^{2}$ \\
\hline \multicolumn{7}{|l|}{ Young (kits and yearlings) } \\
\hline Intercept & 4.673 & 0.256 & 4.172 & 5.174 & 0.87 & 0.93 \\
\hline Captures & 0.078 & 0.109 & -0.135 & 0.291 & & \\
\hline Years of monitoring & 0.011 & 0.020 & -0.028 & 0.050 & & \\
\hline Sex (male) & -0.010 & 0.076 & -0.160 & 0.140 & & \\
\hline Age & 7.997 & 0.201 & 7.603 & 8.391 & & \\
\hline Season (summer) & 3.765 & 0.204 & 3.364 & 4.166 & & \\
\hline Season (autumn) & 5.570 & 0.236 & 5.108 & 6.033 & & \\
\hline Log (territory size) & -0.453 & 0.143 & -0.734 & -0.172 & & \\
\hline Family group size & -0.087 & 0.049 & -0.183 & 0.010 & & \\
\hline \multicolumn{7}{|l|}{ Adults $(2+$ years $)$} \\
\hline Intercept & 21.983 & 0.283 & 21.428 & 22.538 & 0.48 & 0.78 \\
\hline Captures & -0.148 & 0.044 & -0.235 & -0.062 & & \\
\hline Years of monitoring & -0.012 & 0.028 & -0.067 & 0.043 & & \\
\hline Carried telemetry device (yes) & 0.003 & 0.065 & -0.126 & 0.131 & & \\
\hline Sex (male) & -1.084 & 0.253 & -1.581 & -0.587 & & \\
\hline Age & 0.684 & 0.047 & 0.591 & 0.777 & & \\
\hline $\mathrm{Age}^{2}$ & -0.088 & 0.007 & -0.102 & -0.075 & & \\
\hline Social status (subordinate) & -0.539 & 0.179 & -0.889 & -0.189 & & \\
\hline Origin (resident) & 0.001 & 0.096 & -0.186 & 0.188 & & \\
\hline Season (summer) & 0.939 & 0.205 & 0.537 & 1.341 & & \\
\hline Season (autumn) & 1.265 & 0.237 & 0.801 & 1.730 & & \\
\hline Log (territory size) & -0.006 & 0.058 & -0.120 & 0.108 & & \\
\hline Family group size & -0.059 & 0.042 & -0.141 & 0.023 & & \\
\hline Captures: years of monitoring & 0.010 & 0.006 & -0.002 & 0.022 & & \\
\hline Captures: social status (subordinate) & 0.137 & 0.042 & 0.055 & 0.219 & & \\
\hline Captures: age & -0.016 & 0.009 & -0.033 & 0.001 & & \\
\hline Season (summer): sex (male) & 0.462 & 0.268 & -0.064 & 0.987 & & \\
\hline Season (autumn): sex (male) & 0.703 & 0.317 & 0.082 & 1.324 & & \\
\hline Social status (subordinate): age & 0.010 & 0.035 & -0.059 & 0.079 & & \\
\hline
\end{tabular}

Table 2. Effect size ( $\beta$ ), standard error (SE), lower (LCI) and upper (UCI) 95\% confidence interval of explanatory variables for the analysis of body mass in a Eurasian beaver population in south-eastern Norway between 1998 and $2018\left(\mathrm{n}_{\text {young }}=340, \mathrm{n}_{\text {adults }}=916\right)$. Beaver ID, capture year and river were included as random effects. We performed model averaging of best models $(\triangle \mathrm{AICc}<4)$ to estimate the effect size of each variable. Informative parameters are given in bold. Reference level of sex: female. Reference level of season: spring. Reference level of carried telemetry device: no. Reference level of social status: dominant. Reference level of origin: immigrant.

Reproduction. Capture and handling may have further deleterious effects on individuals beyond the immediate event of capture, potentially affecting the following breeding season, but may also have long-term consequences for the reproductive success of handled individuals ${ }^{20}$. We did not find any statistically clear effects of repeated captures and handling on the annual probability of reproducing in our population, which is consistent with results from other long-term studies ${ }^{6,68}$. Studies in ungulates lasting up to 15 years found no evidence of lowered calving success among immobilized individuals ${ }^{8,20}$. However, we did find a decrease in annual litter size with increasing capture and handling events among older individuals. Other studies lasting up to 30 years in ungulates, birds, bears, as well as other species, have similarly showed negative effects on breeding success of repeated capture and handling $17,19,24,52,69,70$. Even though several studies investigated capture and handling effects over several years and seasons, most focus on effects in the current or subsequent breeding season, only assessing short-term effects in species that goes through several seasons. However, capture and handling might induce long-term effects, influencing reproduction in future life-history stages ${ }^{4,71}$. Not evaluating the long-term effects, we risk overlooking important fitness effects ${ }^{9,52}$.

In our study, we found varying capture effects on the reproductive success over more than 20 years of monitoring. Repeated capture and handling had strong negative effects on annual reproduction in the early years of monitoring, which decreased considerably in recent years, indicating habituation to capture and handling stress ${ }^{32,72}$. To our knowledge, similar reproduction responses to repeated capture events have not been observed in other long-term studies, but habituation responses to handling and human activities have been found for behaviour related to breeding in shorebirds ${ }^{73}$ and spatial behaviour and alertness in birds and mammals ${ }^{74-79}$. Some behaviour might even be shaped by parental habituation ${ }^{34}$. Additionally, habituation might be affected by the number of experimenters ${ }^{80}$, requiring thoughtful planning of experimental setups to minimize observational effects. 
a
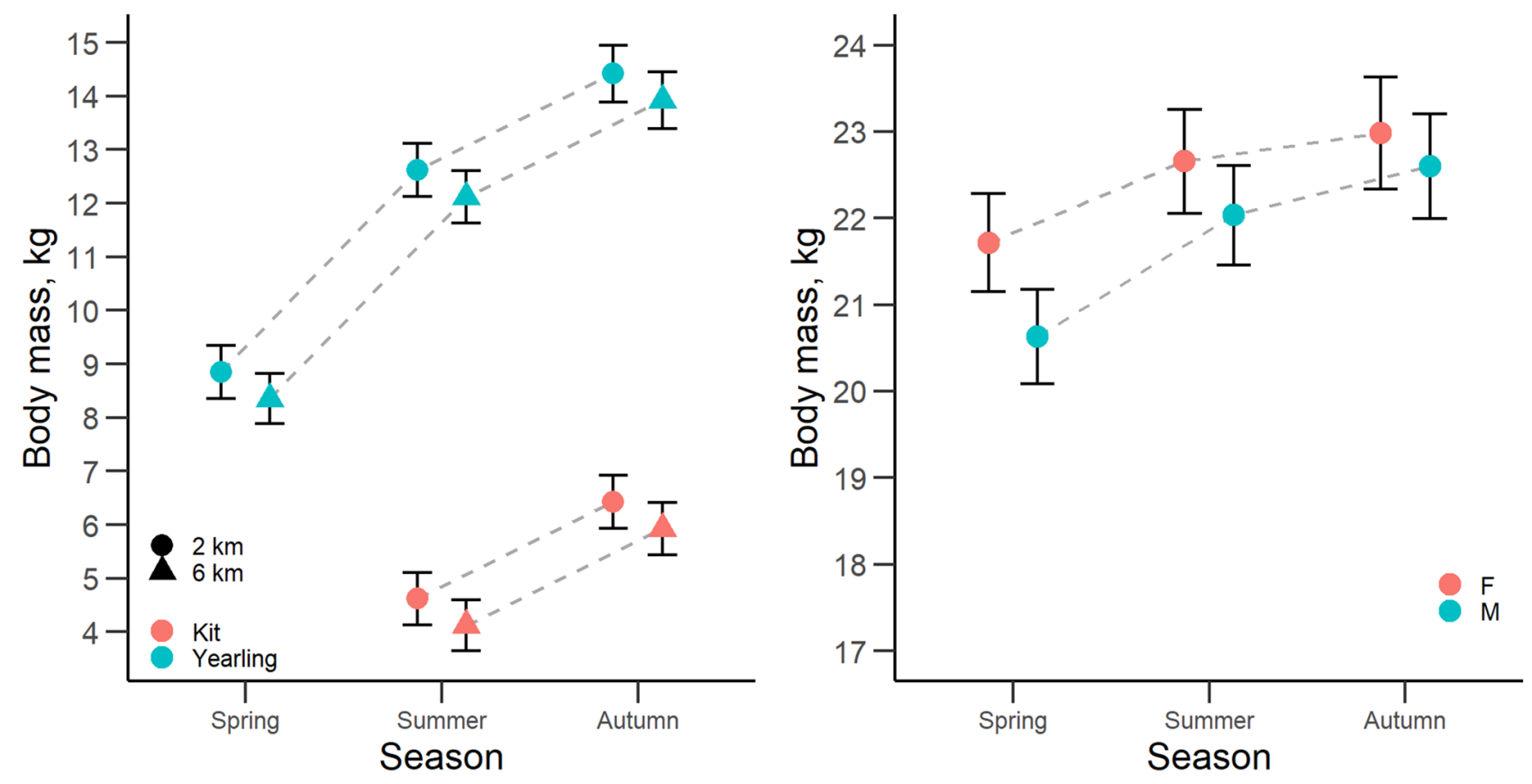

C
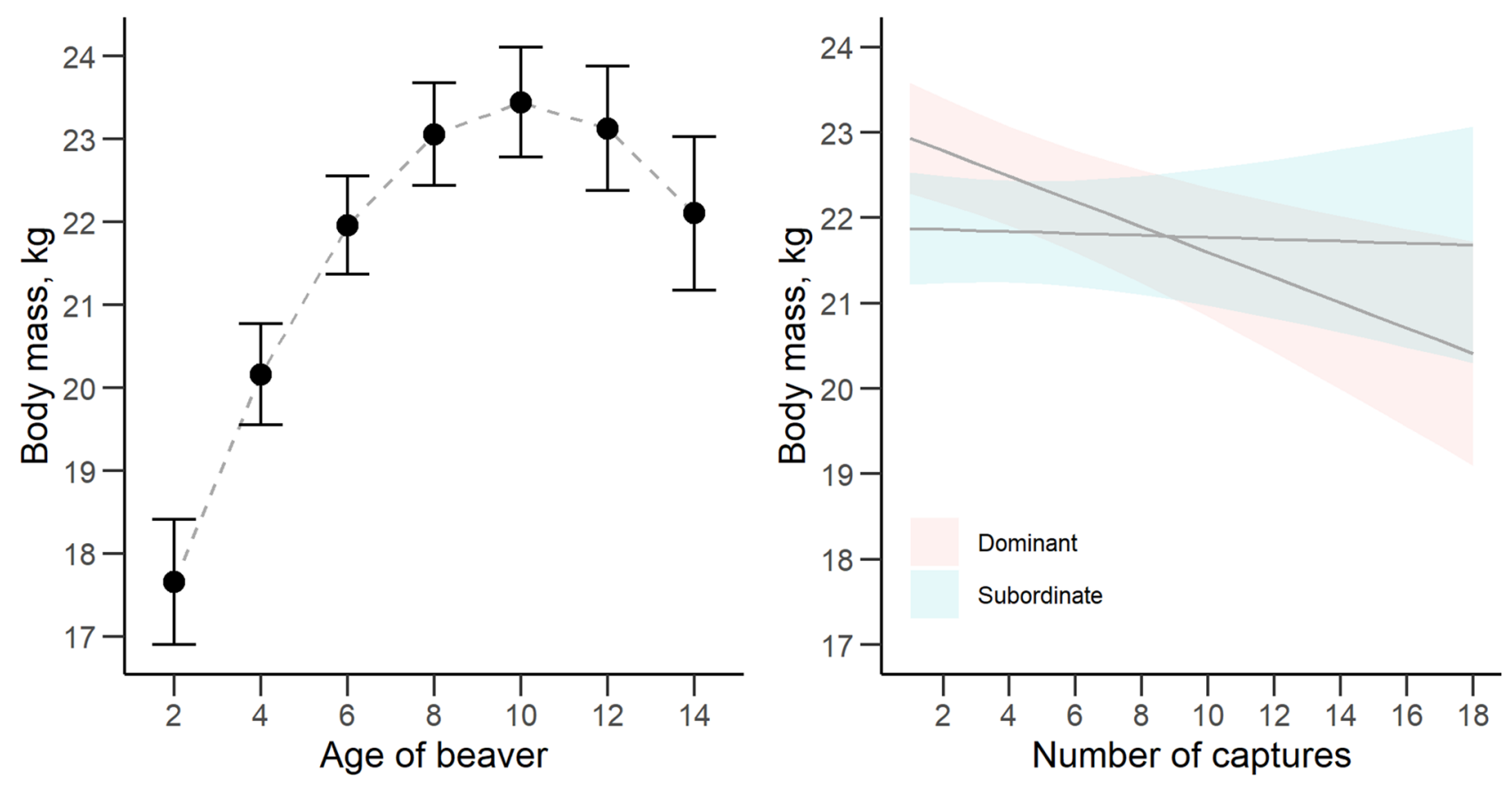

Figure 2. The predicted relationship $\pm 95 \%$ confidence interval between age, territory size and body mass in young beavers (a), between season, sex and body mass in adult beavers (b), between age, and body mass in adult beavers (c) and between number of captures, social status and body mass in adult beavers (d) in a Eurasian beaver population in south-eastern Norway between 1998 and 2018.

Survival. Mortality rates and physical injuries at time of capture are not sufficient to successfully assess capture and handling effects, as animals often hide symptoms to avoid further harm ${ }^{10,11}$. Several studies have found negative effects of capture and handling on survival in birds and mammals in the weeks after capture ${ }^{5,21,23,26,27,29}$ while others observe no effects ${ }^{19,22,28,51,81}$, but most studies do not address long-term effects. A seven year penguin study found decreased annual survival ${ }^{25}$, but survival varied considerably between years, underlining the challenge of finding clear capture and handling effect on survival of individuals ${ }^{10}$. We found no statistically clear short or long-term capture effects on survival in our population. Similar results were found comparing the 


\begin{tabular}{|l|r|l|r|r|r|r|l|}
\hline Variables & Estimate & \multicolumn{1}{l|}{ SE } & \multicolumn{1}{l|}{ LCI } & \multicolumn{1}{l|}{ UCI } & $\mathbf{R}_{\text {marginal }}^{2}$ & $\mathbf{R}_{\text {conditional }}$ \\
\hline Young (kits and yearlings) & $\mathbf{4 0 . 4 1 0}$ & $\mathbf{0 . 8 8 0}$ & $\mathbf{3 8 . 6 8 6}$ & $\mathbf{4 2 . 1 3 4}$ & 0.78 & 0.84 \\
\hline Intercept & 0.018 & 0.199 & -0.372 & 0.408 & & \\
\hline Captures & 0.046 & 0.065 & -0.082 & 0.173 & & \\
\hline Years of monitoring & 0.058 & 0.288 & -0.507 & 0.622 & & \\
\hline Sex (male) & $\mathbf{1 9 . 1 6 4}$ & $\mathbf{0 . 6 1 2}$ & $\mathbf{1 7 . 9 6 5}$ & $\mathbf{2 0 . 3 6 4}$ & & \\
\hline Age & $\mathbf{6 . 2 7 4}$ & $\mathbf{0 . 7 1 5}$ & $\mathbf{4 . 8 7 4}$ & $\mathbf{7 . 6 7 5}$ & & \\
\hline Season (summer) & $\mathbf{1 0 . 5 1 1}$ & $\mathbf{0 . 8 0 1}$ & $\mathbf{8 . 9 4 0}$ & $\mathbf{1 2 . 0 8 2}$ & & \\
\hline Season (autumn) & $-\mathbf{1 . 5 2 8}$ & $\mathbf{0 . 4 7 5}$ & $-\mathbf{2 . 4 5 9}$ & $-\mathbf{0 . 5 9 8}$ & & \\
\hline Log (territory size) & -0.103 & 0.141 & -0.379 & 0.174 & & \\
\hline Family group size & & & & & \\
\hline Adults (2+ years) & $\mathbf{7 8 . 9 5 3}$ & $\mathbf{0 . 3 7 4}$ & $\mathbf{7 8 . 2 2 0}$ & $\mathbf{7 9 . 6 8 6}$ & 0.35 & 0.56 \\
\hline Intercept & -0.018 & 0.051 & -0.117 & 0.081 & & \\
\hline Captures & 0.023 & 0.036 & -0.048 & 0.094 & & \\
\hline Years of monitoring & -0.572 & 0.413 & -1.382 & 0.238 & & \\
\hline Carried telemetry device (yes) & -0.110 & 0.246 & -0.592 & 0.371 & & \\
\hline Sex (male) & $\mathbf{0 . 8 2 6}$ & $\mathbf{0 . 0 9 5}$ & $\mathbf{0 . 6 4 1}$ & $\mathbf{1 . 0 1 2}$ & & \\
\hline Age & $-\mathbf{0 . 1 0 8}$ & $\mathbf{0 . 0 1 1}$ & $-\mathbf{0 . 1 3 1}$ & $-\mathbf{0 . 0 8 6}$ & & \\
\hline Age & 0.072 & 0.319 & -0.553 & 0.698 & & \\
\hline Social status (subordinate) & 0.105 & 0.263 & -0.411 & 0.620 & & \\
\hline Origin (resident) & $\mathbf{1 . 3 7 9}$ & $\mathbf{0 . 2 5 7}$ & $\mathbf{0 . 8 7 6}$ & $\mathbf{1 . 8 8 3}$ & & \\
\hline Season (summer) & $\mathbf{2 . 0 7 7}$ & $\mathbf{0 . 3 1 9}$ & $\mathbf{1 . 4 5 1}$ & $\mathbf{2 . 7 0 3}$ & & \\
\hline Season (autumn) & -0.039 & 0.135 & -0.304 & 0.225 & & \\
\hline Log (territory size) & -0.081 & 0.076 & -0.230 & 0.068 & & \\
\hline Family group size & 0.023 & 0.063 & -0.100 & 0.146 & & \\
\hline Captures: social status (subordinate) & 0.232 & 0.128 & -0.019 & 0.483 & & \\
\hline Social status (subordinate): age & & & & & \\
\hline
\end{tabular}

Table 3. Effect size ( $\beta$ ), standard error (SE), lower (LCI) and upper (UCI) 95\% confidence interval of explanatory variables for the analysis of body size in a Eurasian beaver population in south-eastern Norway between 1998 and $2018\left(\mathrm{n}_{\text {young }}=333, \mathrm{n}_{\text {adults }}=829\right)$. Beaver ID, capture year and river were included as random effects. We performed model averaging of best models $(\triangle \mathrm{AICc}<4)$ to estimate the effect size of each variable. Informative parameters are given in bold. Reference level of sex: female. Reference level of season: spring. Reference level of carried telemetry device: no. Reference level of social status: dominant. Reference level of origin: immigrant.

effects of transmitters over eight years in beavers ${ }^{16}$. However, more details on actual time of death of individuals may reveal capture and handling-related effects that otherwise may go undetected ${ }^{9,52}$.

Social status had a strong impact on annual survival in our population and handling procedures that affect the possibility to obtain or hold a social rank might have considerable consequences ${ }^{7}$. Subordinate individuals may be more challenged than territory holders to find a territory of their own, which may result in lower survival or accepting a territory of lesser quality as seen in other rodents ${ }^{82}$. Being potentially physiologically pressured (e.g. from growing) and operating in a highly tense social landscape ${ }^{83}$, we would expect high capture intensity in combination to further affect survival ${ }^{7}$, whereas dominant individuals might be more socially anchored in a territory and therefore more resilient ${ }^{82}$. We found a statistically clear decrease in survival of subordinates with increasing age and with increasing family group size which indicate they might be better off leaving their family group after some time. Subordinate beavers have been shown to make explorative trips to neighbouring and distant territories before they disperse from their natal family group ${ }^{84}$ and might experience increased mortality risk when exploring potential territories ${ }^{85-87}$.

Dominant individuals might need time to establish in a territory and build up their family group. Accordingly, we found a higher probability of staying dominant for individuals in larger family groups. A high number of individuals in a territory might indicate high territory quality ${ }^{88}$ which the prolonged territory occupancy might reflect. Furthermore, the relationship between larger family groups and territory occupancy might reflect the benefits of social behaviour in beavers ${ }^{89}$. Other rodent studies found an increased survival and reproductive success among individuals that were translocated to new territories together with familiar conspecifics ${ }^{90,91}$. Not surprisingly, the probability of keeping dominance decreased with increasing age, indicating senescence ${ }^{83,92}$.

\section{Conclusion}

Using a semi-aquatic mammal as a model species, we here present clear insights on how long-term monitoring studies including repeated capturing and handling of individuals affect the wellbeing of wild animal populations by evaluating changes in several fitness-related parameters. Our results, based on more than 20 years of a unique long-term individual-based field study, show how repeated capture and handling can have clear effects on 

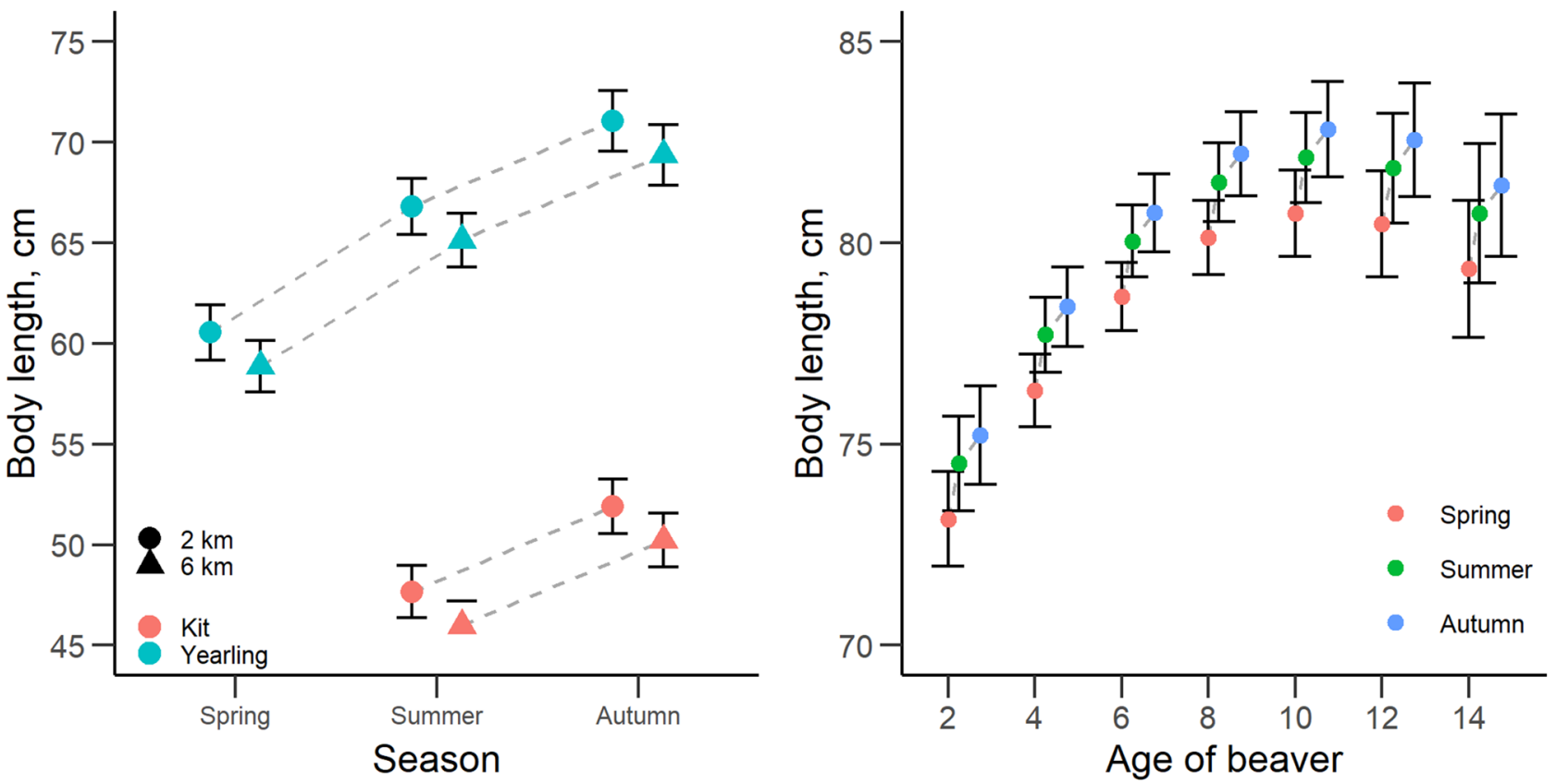

Figure 3. The predicted relationship $\pm 95 \%$ confidence interval between age, territory size and body length in young beavers (a) and between age, season and body length in adult beavers (b) in a Eurasian beaver population in south-eastern Norway between 1998 and 2018.

important life stages in a semi-aquatic mammal. We illustrate the validity of long-term individual-based studies which have great potential in the planning and execution of future wildlife and conservation studies to promote the welfare of wild populations and ensure reliable research data ${ }^{12}$.

Long-term individual-based studies should always evaluate the potential bias created. Our results confirm the importance of having a clear adaptive objective when assessing effects of repeated capture and handling. Setting clear objectives and framing tractable questions will help resolve on what to monitor and assess, allowing the monitoring program to evolve and develop in response to new information and new questions ${ }^{93}$.

\section{Methods}

Study animal. Beavers are socially monogamous, semi-aquatic nocturnal mammals that inhabit various freshwater bodies ${ }^{42}$. They live in family groups consisting of the dominant breeding pair, kits of the year and older non-breeding offspring ${ }^{94}$. Beavers reach sexual maturity during their second winter ${ }^{37}$ and give birth to one to five kits in mid-May, which emerge from the lodge during July when they start feeding on their own on twigs and leaves of deciduous trees like the adults ${ }^{94}$. Around 2-3 years old, beavers disperse to establish a territory of their own ${ }^{84,95}$.

Beavers are highly territorial and announce territory occupation mainly by scent marking, primarily at territorial borders ${ }^{39}$. All adults take part in territorial defence, but males allocate more time to patrolling and scent marking ${ }^{46}$.

Study site. Our study site is located at the lower reaches of the rivers Straumen, Gvarv and Sauar in Vestfold and Telemark County, south-eastern Norway. The river sections are generally slow flowing with stable water levels, have similar depth structure and are 20-150 $\mathrm{m}$ wide ${ }^{96}$. All rivers contain natural lakes and man-made impoundments along part of their length, resulting in only limited water temperature fluctuations along the main river channels ${ }^{96}$. The rivers flow through small towns, farms and fields interspersed with riparian woodland ${ }^{44,45}$.

Beavers have inhabited the rivers since the 1920 s where they recolonized the rivers. The population is at carrying capacity, as territories of various sizes border each other directly ${ }^{94}$. Territory borders are identified based on scent mound concentrations, sight observations of patrolling known beavers and GPS data.

Capture protocol. Since 1997, beavers in the area have been monitored through an extensive live-trapping program (the Norwegian Beaver Project, NBP). The long-term monitoring project aims to annually capture all newcomers (kits and dispersers from outside the study site) to enable identification at later encounters, as well as annually record family group sizes.

Captures were conducted at night. Individuals were detected from a motorboat using searchlights and captured using large landing-nets in shallow water or on land ${ }^{97}$. Captured individuals were immobilized in cloth sacks, enabling easy handling without anaesthesia. Beavers were weighed to the nearest $100 \mathrm{~g}$. Body length was 


\begin{tabular}{|l|l|l|l|l|l|l|l|}
\hline Variables & Estimate & SE & LCI & UCI & $\mathbf{R}_{\text {marginal }}^{2}$ & $\mathbf{R}_{\text {conditional }}$ \\
\hline Probability of reproducing & $-\mathbf{0 . 6 6 9}$ & $\mathbf{0 . 3 0 9}$ & $-\mathbf{1 . 2 7 4}$ & $-\mathbf{0 . 0 6 3}$ & 0.08 & 0.14 \\
\hline Intercept & -0.100 & 0.056 & -0.210 & 0.010 & & \\
\hline Captures & 0.018 & 0.034 & -0.049 & 0.085 & & \\
\hline Years of monitoring & 0.232 & 0.335 & -0.425 & 0.889 & & \\
\hline Carried telemetry device (yes) & -0.072 & 0.233 & -0.530 & 0.385 & & \\
\hline Log (age) & -0.083 & 0.227 & -0.528 & 0.363 & & \\
\hline Origin (resident) & 0.399 & 0.263 & -0.117 & 0.914 & & \\
\hline Log (territory size) & 0.019 & 0.047 & -0.074 & 0.111 & & \\
\hline Family group size & 0.131 & 0.232 & -0.325 & 0.586 & & \\
\hline Reproduced previous year (yes) & 0.026 & $\mathbf{0 . 0 0 9}$ & $\mathbf{0 . 0 0 9}$ & $\mathbf{0 . 0 4 3}$ & & \\
\hline Captures: years of monitoring & $\mathbf{0 . 0 2 6}$ & -0.060 & 0.095 & -0.247 & 0.127 & & \\
\hline Captures: log(age) & & & & & & \\
\hline Annual litter size & $-\mathbf{0 . 6 2 0}$ & $\mathbf{0 . 2 2 5}$ & $-\mathbf{1 . 0 6 2}$ & $-\mathbf{0 . 1 7 9}$ & 0.09 & 0.21 \\
\hline Intercept & -0.007 & 0.040 & -0.084 & 0.071 & & \\
\hline Captures & 0.004 & 0.025 & -0.045 & 0.053 & & \\
\hline Years of monitoring & 0.049 & 0.143 & -0.231 & 0.329 & & \\
\hline Carried telemetry device (yes) & -0.041 & 0.030 & -0.099 & 0.017 & & \\
\hline Log (age) & -0.185 & 0.250 & -0.674 & 0.305 & & \\
\hline Origin (resident) & 0.196 & 0.179 & -0.155 & 0.548 & & \\
\hline Log (territory size) & 0.007 & 0.023 & -0.039 & 0.053 & & \\
\hline Family group size & 0.046 & 0.108 & -0.167 & 0.259 & & \\
\hline Reproduced previous year (yes) & $\mathbf{0 . 0 2 1}$ & $\mathbf{0 . 0 0 6}$ & $\mathbf{0 . 0 1 0}$ & $\mathbf{0 . 0 3 2}$ & & \\
\hline Captures: years of monitoring & $-\mathbf{0 . 0 1 9}$ & $\mathbf{0 . 0 0 7}$ & $-\mathbf{0 . 0 3 4}$ & $-\mathbf{0 . 0 0 5}$ & & \\
\hline Captures: log(age) & & & & & \\
\hline
\end{tabular}

Table 4. Effect size ( $\beta$ ), standard error (SE), lower (LCI) and upper (UCI) 95\% confidence interval of explanatory variables for the analysis of reproduction in a Eurasian beaver population in south-eastern Norway between 1998 and $2018(\mathrm{n}=388)$. Beaver ID, monitoring year and river were included as random effects. We performed model averaging of best models $(\triangle \mathrm{AICc}<4)$ to estimate the effect size of each variable. Informative parameters are given in bold. Reference level of carried telemetry device: no. Reference level of origin: immigrant. Reference level of reproduced previous year: no.

measured following the curvature of the spine from nose tip to the base of the tail. Tail length was measured from the base to the tip of the tail and tail width was measured from edge to edge of the dorsal surface at the midpoint between tail base and tip.

When encountering individuals, samples of castoreum and anal gland secretion were obtained. Hair samples from the lower back were obtained at an individual's first encounter. Furthermore, some adults participated in short-term experiments involving deployment of various data-loggers and transmitters. Unfamiliar individuals were sexed based on the colour of their anal gland secretion ${ }^{98}$, and tagged with microchips and unique combinations of plastic and metal ear-tags. Individuals first captured as kit or yearling were given an exact age. Older individuals ( $\geq 2$ years) were assigned a minimum age based on body mass when first captured ${ }^{99}$; minimum 2 years (subadult) when $\geq 17$ and $\leq 19.5 \mathrm{~kg}$ and minimum 3 years (adult) when $>19.5 \mathrm{~kg}$. Dominance was in most cases attributed to adult territorial residents of each sex. Dominance was otherwise verified by eventual dispersal of the alternative candidate, greatest body weight among same-sex group members or lactation in females (large nipples). Individuals dispersing into a territory were posited to have achieved the dominant breeding position when the previous dominant of the same sex had disappeared or evidence outlined above were applicable. Unless proven otherwise, dominant individuals were assumed to maintain their status until they disappeared or died ${ }^{100}$. Captured beavers were released near capture site within their territory after 20-40 min of handling time $\mathrm{e}^{97}$.

Ethical note. All capture and handling procedures were approved by the Norwegian Experimental Animal Board (Most recent authorization: FOTS ID15947) and by the Norwegian Directorate for Nature Management (Most recent authorization: 2014/14415). Our study met the ASAB/ABS Guidelines for the treatment of animals in behavioural research and teaching ${ }^{101}$. No captured individuals were injured during capture and handling, and all were successfully released afterwards. All methods were performed in accordance with the relevant guidelines and regulations.

Body condition indices. The beaver tail functions as fat storage ${ }^{102}$. Tail size (length $\times$ width) varies with season and is positively correlated with body mass ${ }^{56}$. Using the ratio of the tail size (seasonally variable) to body length (seasonally stable) as an index of tail fat content, tail size has been used as proxy for body condition ${ }^{37,103}$. Larger tail fat index thus indicates higher tail fat content and better body condition. 
a

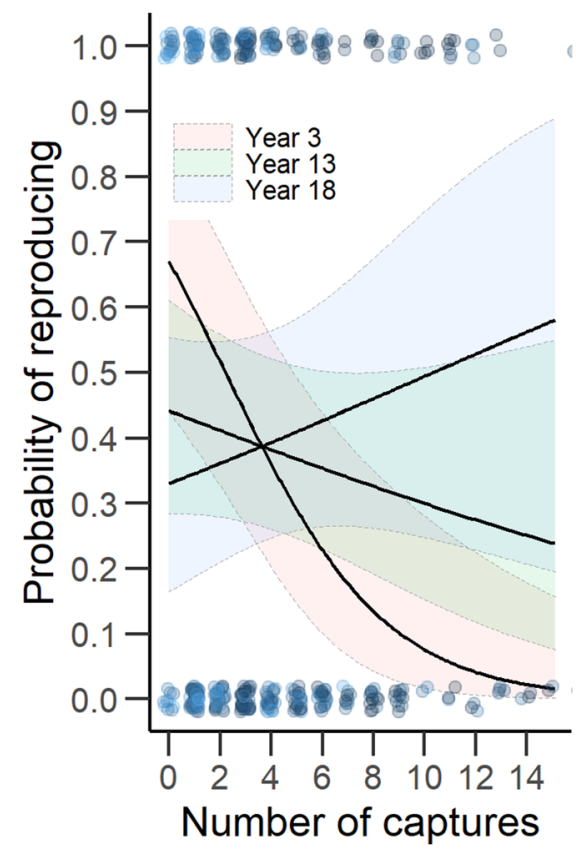

b

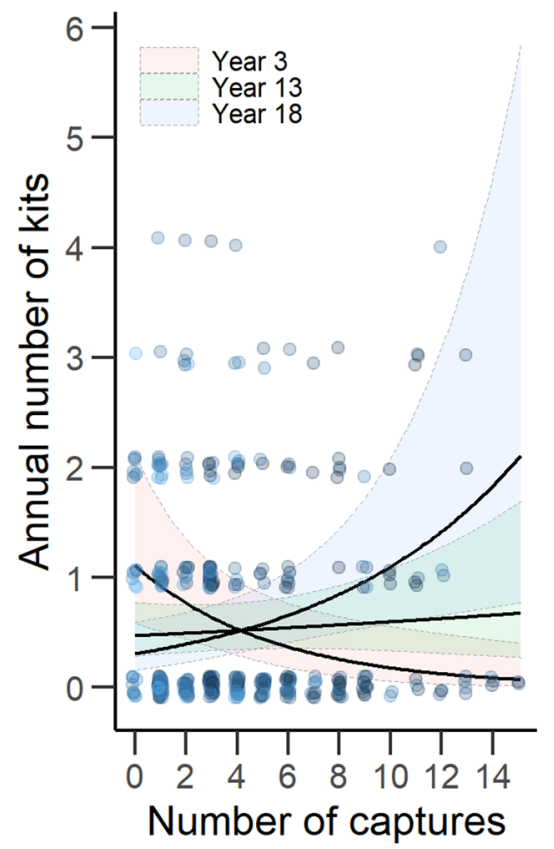

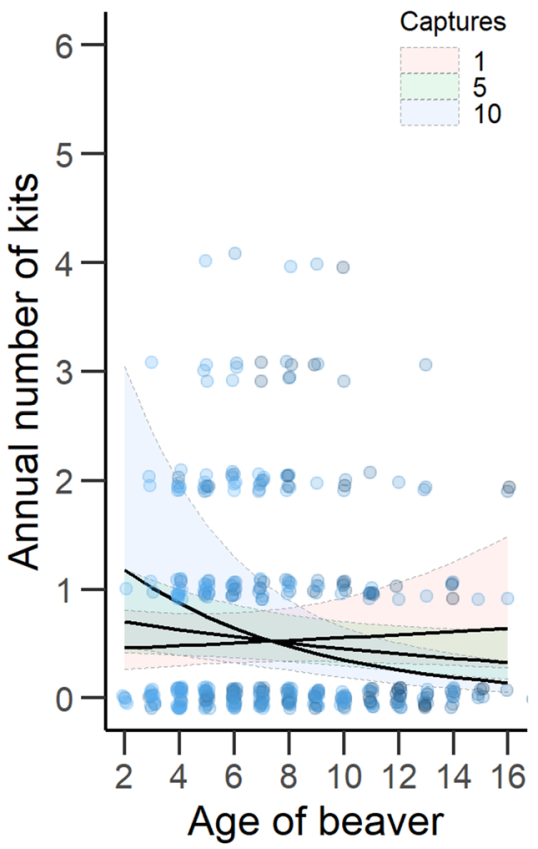

Figure 4. The predicted relationship $\pm 95 \%$ confidence interval between number of captures, years of monitoring and probability of reproducing (a) and annual litter size (b), and between number of captures, age and probability of reproducing (c) in a Eurasian beaver population in south-eastern Norway between 1998 and 2018. Points represent the actual observations with small random variation for better visualisation. Darker colours increase with $(\mathbf{a}, \mathbf{b})$ increasing years of monitoring and $(\mathbf{c})$ increasing number of captures.

\begin{tabular}{|l|l|l|l|l|l|}
\hline Variables & Estimate & SE & LCI & UCI & Tjur's R $^{2}$ \\
\hline \multicolumn{7}{|l|}{ Probability of survival } & -2.372 & $\mathbf{0 . 2 0 0}$ & -2.765 & $-\mathbf{1 . 9 8 0}$ & 0.07 \\
\hline Intercept & $\mathbf{0 . 1 1 1}$ & $\mathbf{0 . 0 3 9}$ & $\mathbf{0 . 0 3 5}$ & $\mathbf{0 . 1 8 7}$ & \\
\hline Age & $\mathbf{0 . 8 5 7}$ & $\mathbf{0 . 2 3 0}$ & $\mathbf{0 . 4 0 7}$ & $\mathbf{1 . 3 0 7}$ & \\
\hline Social status (subordinate) & $-\mathbf{0 . 0 9 1}$ & $\mathbf{0 . 0 3 5}$ & $-\mathbf{0 . 1 5 9}$ & $-\mathbf{0 . 0 2 2}$ & \\
\hline Family group size & $-\mathbf{0 . 2 0 1}$ & $\mathbf{0 . 0 5 4}$ & $-\mathbf{0 . 3 0 7}$ & $-\mathbf{0 . 0 9 4}$ & \\
\hline Social status (subordinate): age &
\end{tabular}

Table 5. Effect size ( $\beta$ ), standard error (SE), lower (LCI) and upper (UCI) 95\% confidence interval of explanatory variables for the continuous time capture-recapture analysis of annual survival in a Eurasian beaver population in south-eastern Norway between 1998 and $2018(n=1145)$. Informative parameters are given in bold. Reference level of Social status: Dominant.

However, body mass and body length may vary differently than tail fat in relation to long-term capture and handling effects. Body length was not recorded in a few capturing events ( 21 individuals), but tail size was measured. In those cases, we interpolated body length between measures within the individual in an age group (i.e., kit, yearling, subadult and adult) and excluded observations if interpolation was not possible within the age group.

Since young and adults are not treated equally in our protocol and may be affected by different ecological factors, we chose to divide our analyses on body condition indices into young (kits and yearlings) and adults (subadults and adults) to balance the data set.

Reproduction. Each year we aimed to capture all kits and yearlings not captured during their first year. We recorded annual reproductive success for breeding pairs in each territory as the number of kits in a given year, based on the number of captured and observed kits plus unmarked yearlings captured the following year.

Survival. Using observations from the capture protocol in a capture-mark-recapture (CMR) framework, we can estimate apparent survival in the population, which may reflect actual survival, but also emigration from the study area ${ }^{104-106}$.

As dispersal is a dangerous period during the life of an animal, which may result in high mortality ${ }^{107,108}$, territory occupancy of dominant individuals may be used as proxy for survival assuming dominant individuals perished when they lost territory occupancy and did not overtake a new territory ${ }^{83}$. 

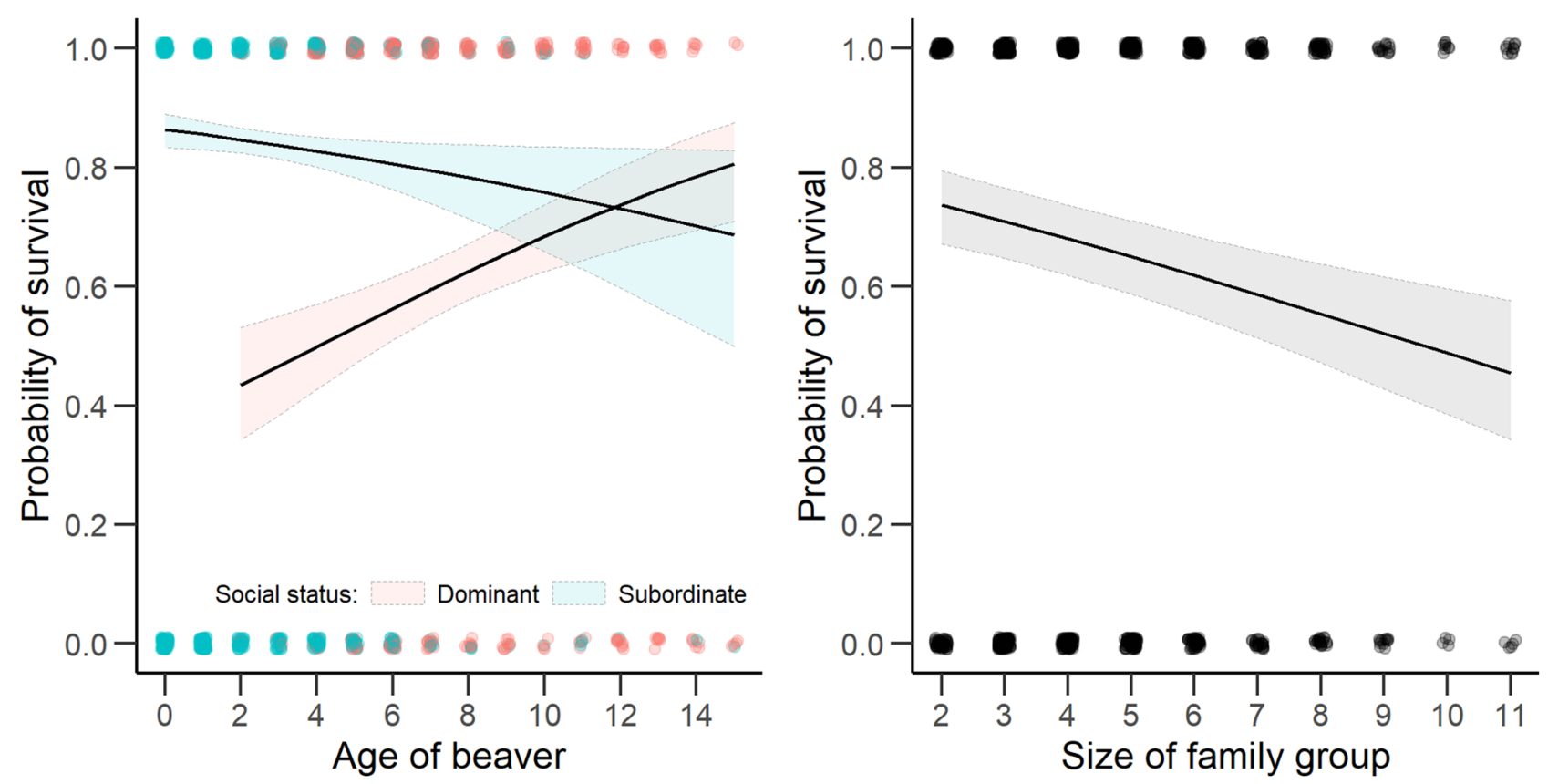

Figure 5. The predicted relationship $\pm 95 \%$ confidence interval between age, social status and survival probability (a) and between family group size and survival probability (b) in a Eurasian beaver population in south-eastern Norway between 1998 and 2018. Points represent the actual observations with small random variation for better visualisation.

\begin{tabular}{|l|r|l|r|r|l|l|l|}
\hline Variables & Estimate & SE & \multicolumn{1}{l|}{ LCI } & UCI & $\mathbf{R}_{\text {marginal }}^{2}$ & $\mathbf{R}_{\text {conditional }}^{2}$ \\
\hline Probability of staying dominant the following year \\
\hline Intercept & $\mathbf{3 . 6 3 7}$ & $\mathbf{0 . 4 2 8}$ & $\mathbf{2 . 7 9 7}$ & $\mathbf{4 . 4 7 6}$ & 0.19 & 0.25 \\
\hline Captures & 0.020 & 0.059 & -0.095 & 0.136 & & \\
\hline Years of monitoring & -0.062 & 0.040 & -0.140 & 0.016 & & \\
\hline Carried telemetry device (yes) & -0.054 & 0.195 & -0.436 & 0.328 & & \\
\hline Sex (male) & 0.017 & 0.101 & -0.181 & 0.215 & & \\
\hline Age & $-\mathbf{0 . 1 6 4}$ & $\mathbf{0 . 0 3 7}$ & $-\mathbf{0 . 2 3 6}$ & $-\mathbf{0 . 0 9 1}$ & & \\
\hline Origin (resident) & -0.101 & 0.216 & -0.523 & 0.322 & & \\
\hline log(territory size) & -0.441 & 0.251 & -0.932 & 0.050 & & \\
\hline Family group size & $\mathbf{0 . 2 9 1}$ & $\mathbf{0 . 0 8 5}$ & $\mathbf{0 . 1 2 4}$ & $\mathbf{0 . 4 5 8}$ & & \\
\hline Captures: years of monitoring & 0.001 & 0.004 & -0.007 & 0.008 & & \\
\hline Captures: carried telemetry device (yes) & 0.004 & 0.031 & -0.058 & 0.065 & & \\
\hline Captures: age & -0.002 & 0.005 & -0.012 & 0.009 & & \\
\hline
\end{tabular}

Table 6. Effect size ( $\beta$ ), standard error (SE), lower (LCI) and upper (UCI) 95\% confidence interval of explanatory variables for the analysis of staying dominant the following year in a Eurasian beaver population in south-eastern Norway between 1998 and $2018(n=773)$. Beaver ID, monitoring year and river were included as random effects. We performed model averaging of best models $(\triangle \mathrm{AICc}<4)$ to estimate the effect size of each variable. Informative parameters are given in bold. Reference level of sex: Female. Reference level of carried telemetry device: No. Reference level of origin: Immigrant.

Statistical analysis. For all analyses on body condition, reproduction and dominance status we used linear mixed-effects models (LMM) and generalized linear mixed-effects models (GLMM) with capture year, beaver ID and study river as random effects to account for variability between years, individuals and study sites that might be caused by climatic differences, habitat quality or sampling frequency.

We investigated how capture and handling affected tail fat index, body mass and body length using LMMs for young and adult individuals, respectively. For young individuals we analysed how the number of capture and handling events and years of monitoring (years since 1997) affected the tail fat index, body mass and body length of individuals. Capture season (spring: March-May, summer: June-August, autumn: September-November), sex, age, territory size (km bank length) and family group size were included to account for important ecological factors. Similar LMMs were built for adults, additionally analysing the effect of carrying a telemetry device (yes/ 

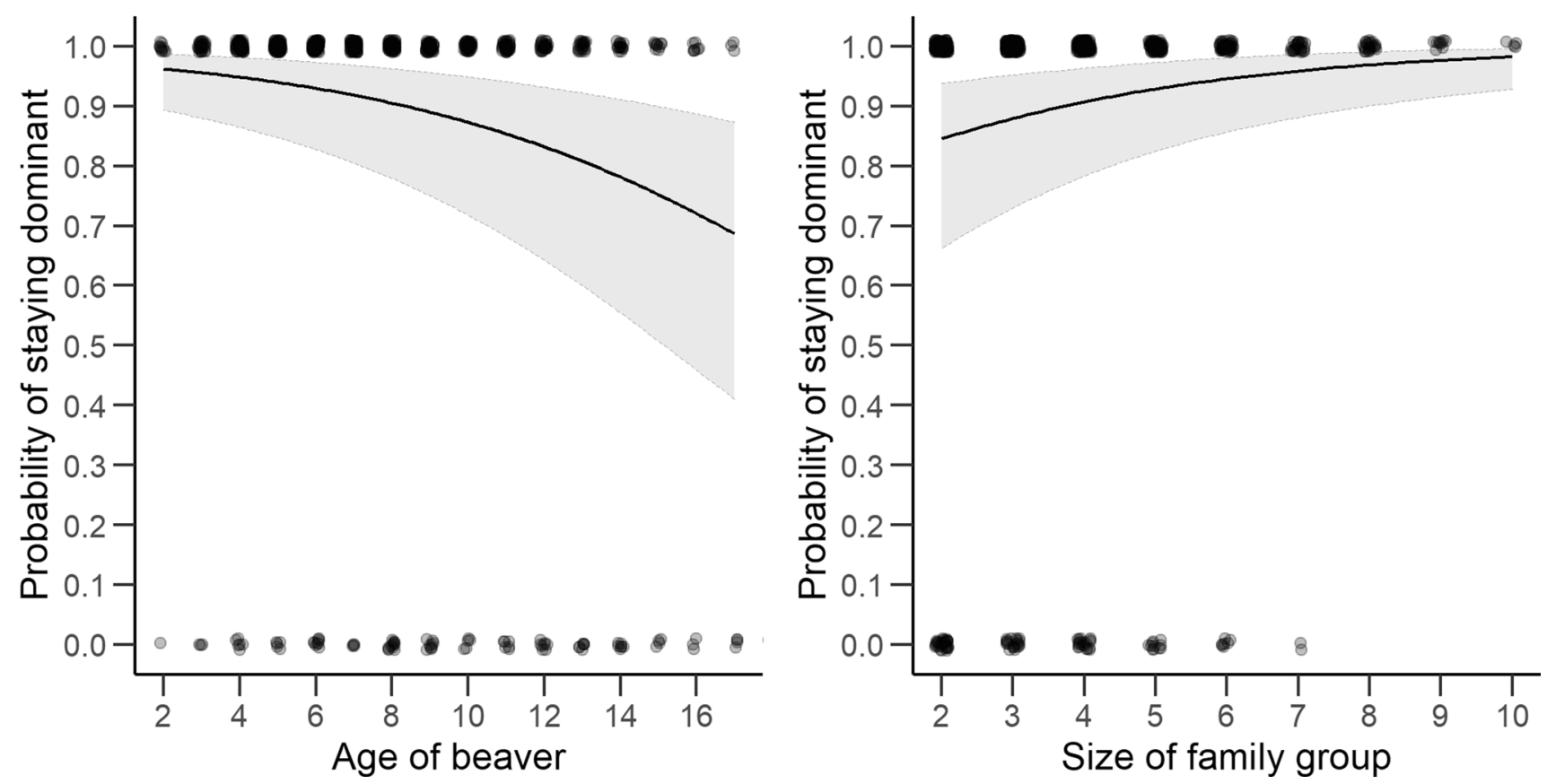

Figure 6. The predicted relationship $\pm 95 \%$ confidence interval between age (a), family group size (b) and probability of keeping dominance in a Eurasian beaver population in south-eastern Norway between 1998 and 2018. Points represent the actual observations with small random variation for better visualisation.

no) in its lifetime up to the given capture event, accounting for social status of the beaver (dominant/subordinate) at the capture event and the individual's family origin (immigrant or resident).

To investigate effects of long-term capture and handling on annual reproduction, we used a GLMM with binomial distribution and logit link ( $1=$ reproducing dominant females, $0=$ non-reproducing dominant females), analysing the relative importance of number of capture and handling events, years of monitoring and whether the animal had carried a telemetry device in its life time. We included age of the beaver, whether the female reproduced the previous year, territory size family origin and size of family group. The same covariates were included in a GLMM with Poisson distribution and log link to analyse the effect of long-term captures and handling on annual reproductive success (i.e. litter size).

To investigate effects of long-term capture and handling on dominance status, we used a GLMM with binomial distribution and logit link $(1=$ individuals that kept dominance in the following year, $0=$ individuals that lost dominance in the following year), analysing the relative importance of number of capture and handling events, years of monitoring and whether the animal had carried a telemetry device in its life time for keeping dominance status the following year, including effects of sex, age, territory size, family origin and family group size.

The fixed effects used in all analyses were not correlated (Pearson $r$ coefficient $<0.6$ ) and variance inflation factor values were $<3^{109}$.

A list of candidate models was created using ecologically relevant combinations of fixed effects. Variables were included to account for variability in endogenous (such as sex, age and social status) and exogenous factors (such as territory size, family group size, family origin and season) that are important for describing the ecology of the beaver. Years since 1997 (years of monitoring) were included to capture the long-term effects of our capture protocol, as the monitoring may not only affect individuals that are monitored at a given time but may also affect future generations. Years of monitoring for a given individual at a given time is implicitly within the age of the beaver $(r=0.9)$ and in the number of captures $(r=0.7)$. Linearity of variables were tested in univariable mixed-effect models with either linear or squared variables. We included interactions to capture the variability in how the beavers reacts to capture and handling events on a long term (Captures $\times$ Years of monitoring), and the variability in how males, females, dominants and subordinates, young and old may react to repeated capture and handling events (Captures $\times$ Sex, Captures $\times$ Social status, Capture $\times$ Age, respectively). Furthermore, we included interactions to account for ecological differences between males and females over the year (Season $\times$ Sex) and the variability for social status at different ages (Social status $\times$ Age), as there is a higher degree of subordinates among young individuals and a higher degree of dominants among older individuals.

Model selection was based on Akaike's Information Criterion corrected for small sample size ${ }^{110}$, and carried out using the R packages glmmTMB ${ }^{111}$ and MuMIn ${ }^{112}$. If $\triangle \mathrm{AICc}$ was $<4$ in two or more of the most parsimonious models, we performed model averaging ${ }^{110,113}$. Parameters that included zero within their $95 \%$ confidence interval (CI) were considered uninformative ${ }^{113}$. The most parsimonious models were visually validated using the $\mathrm{R}$ package DHARMa ${ }^{114}$ to plot standardised model residuals against the fitted values ${ }^{109}$. Models for reproduction 
and dominance status were furthermore checked for zero-inflation using DHARMa. Top candidate models for all analyses can be found in the supporting material.

Survival probability was modeled in a CMR framework. Since classical CMR models require discrete-time assumptions ${ }^{106}$ that introduce constraints in CMR protocols that are not always compatible with the reality ${ }^{104,105}$, we chose to fit our survival model in a continuous time capture-recapture model using the R-package CMRCT

${ }^{104}$, enabling us to estimate the apparent annual survival in our population. We modeled how the importance of repeated capture and handling events, years of monitoring and carrying a telemetry device in its lifetime affected apparent survival. Capture season, sex, age, territory size and family group size were included to account for important ecological factors. Furthermore we included interactions described above (Supplementary information S1).

As CMRCT currently does not offer any model selection, we fitted all variables and interactions in a global model and removed uninformative parameters by backwards selection until the model consisted only of informative parameters. Parameters that included zero within their $95 \%$ confidence interval (CI) were considered uninformative ${ }^{113}$.

All analyses were conducted in R 3.6.3 $3^{115}$.

\section{Data availability}

Data is available at https://doi.org/10.23642/usn.13083782.

Received: 11 June 2020; Accepted: 8 October 2020

Published online: 21 October 2020

\section{References}

1. Jobling, M. Are compensatory growth and catch-up growth two sides of the same coin?. Aquacult. Int. 18, 501-510. https://doi. org/10.1007/s10499-009-9260-8 (2010).

2. Rebke, M., Coulson, T., Becker, P. H. \& Vaupel, J. W. Reproductive improvement and senescence in a long-lived bird. Proc. Natl. Acad. Sci. 107, 7841-7846. https://doi.org/10.1073/pnas.1002645107 (2010).

3. Farias, V., Fuller, T. K., Wayne, R. K. \& Sauvajot, R. M. Survival and cause-specific mortality of gray foxes (Urocyon cinereoargenteus) in southern California. J. Zool. 266, 249-254. https://doi.org/10.1017/S0952836905006850 (2005).

4. Clutton-Brock, T. \& Sheldon, B. C. Individuals and populations: the role of long-term, individual-based studies of animals in ecology and evolutionary biology. Trends Ecol. Evol. 25, 562-573. https://doi.org/10.1016/j.tree.2010.08.002 (2010).

5. Arnemo, J. M. et al. Risk of capture-related mortality in large free-ranging mammals: experiences from Scandinavia. Wildl. Biol. 12, 109-113. https://doi.org/10.1017/S0952836901000309 (2006).

6. Harcourt, R. G., Turner, E., Hall, A., Waas, J. R. \& Hindell, M. Effects of capture stress on free-ranging, reproductively active male Weddell seals. J. Comp. Physiol. A. 196, 147-154. https://doi.org/10.1007/s00359-009-0501-0 (2010).

7. Pelletier, F., Hogg, J. T. \& Festa-Bianchet, M. Effect of chemical immobilization on social status of bighorn rams. Anim. Behav. 67, 1163-1165. https://doi.org/10.1016/j.anbehav.2003.07.009 (2004).

8. Brivio, F., Grignolio, S., Sica, N., Cerise, S. \& Bassano, B. Assessing the impact of capture on wild animals: the case study of chemical immobilisation on alpine ibex. PLoS ONE 10, e0130957. https://doi.org/10.1371/journal.pone.0130957 (2015).

9. Cattet, M., Boulanger, J., Stenhouse, G., Powell, R. A. \& Reynolds-Hogland, M. J. An evaluation of long-term capture effects in ursids: implications for wildlife welfare and research. J. Mammal. 89, 973-990. https://doi.org/10.1644/08-MAMM-A-095.1 (2008).

10. Holt, R. D. et al. Estimating duration of short-term acute effects of capture handling and radiomarking. J. Wildl. Manag. 73, 989-995. https://doi.org/10.2193/2008-073 (2009).

11. Jordan, B. Science-based assessment of animal welfare: wild and captive animals. Revue Sci. Tech. Office Int. Des. Epizooties 24, 515. https://doi.org/10.20506/rst.24.2.1588 (2005).

12. Jewell, Z. Effect of monitoring technique on quality of conservation science. Conserv Biol 27, 501-508. https://doi.org/10.1111/ cobi.12066 (2013).

13. Wilson, R. P. \& McMahon, C. R. Measuring devices on wild animals: what constitutes acceptable practice?. Front Ecol. Environ. 4, 147-154 (2006).

14. Bourbonnais, M. L. et al. Environmental factors and habitat use influence body condition of individuals in a species at risk, the grizzly bear. Conserv. Physiol. 2, 1. https://doi.org/10.1093/conphys/cou043 (2014).

15. Pearson, E., Ortega, Y. K. \& Ruggiero, L. F. Trap-induced mass declines in small mammals: mass as a population index. J. Wildl. Manag. 1, 684-691. https://doi.org/10.2307/3802675 (2003).

16. Smith, J. B., Windels, S. K., Wolf, T., Klaver, R. W. \& Belant, J. L. Do transmitters affect survival and body condition of American beavers Castor canadensis?. Wildl. Biol 22, 117-123. https://doi.org/10.2981/wlb.00160 (2016).

17. Alibhai, S. K., Jewell, Z. C. \& Towindo, S. S. Effects of immobilization on fertility in female black rhino (Diceros bicornis). J. Zool. 253, 333-345 (2001).

18. Carey, M. J. The effects of investigator disturbance on procellariiform seabirds: a review. N. Z. J. Zool. 36, 367-377. https://doi. org/10.1080/03014220909510161 (2009).

19. Côté, S. D., Festa-Bianchet, M. \& Fournier, F. Life-history effects of chemical immobilization and radiocollars on mountain goats. J. Wildl. Manag. 1, 745-752. https://doi.org/10.2307/3802351 (1998).

20. Omsjoe, E. H. et al. Evaluating capture stress and its effects on reproductive success in Svalbard reindeer. Can. J. Zool. 87, 73-85. https://doi.org/10.1139/Z08-139 (2009).

21. Sharpe, F., Bolton, M., Sheldon, R. \& Ratcliffe, N. Effects of color banding, radio tagging, and repeated handling on the condition and survival of Lapwing chicks and consequences for estimates of breeding productivity. J. Field Ornithol. 80, 101-110. https:// doi.org/10.1111/j.1557-9263.2009.00211.x (2009).

22. Igual, J. M. et al. Short-term effects of data-loggers on Cory's shearwater (Calonectris diomedea). Mar. Biol. 146, 619-624 (2005).

23. Casas, F. et al. Assessing the short-term effects of capture, handling and tagging of sandgrouse. Ibis 157, 115-124. https://doi. org/10.1111/ibi.12222 (2015).

24. Clinchy, M., Krebs, C. J. \& Jarman, P. J. Dispersal sinks and handling effects: interpreting the role of immigration in common brushtail possum populations. J. Anim. Ecol. 70, 515-526. https://doi.org/10.1046/j.1365-2656.2001.00510.x (2001).

25. Dugger, K. M., Ballard, G., Ainley, D. G. \& Barton, K. J. Effects of flipper bands on foraging behavior and survival of Adélie penguins (Pygoscelis adeliae). Auk 123, 858-869. https://doi.org/10.1093/auk/123.3.858 (2006).

26. Esler, D., Mulcahy, D. M. \& Jarvis, R. L. Testing assumptions for unbiased estimation of survival of radiomarked harlequin ducks. J. Wildl. Manag. 1, 591-598. https://doi.org/10.2307/3803257 (2000). 
27. Gibson, D. et al. Effects of radio collars on survival and lekking behavior of male greater sage-grouse. The Condor 115, 769-776. https://doi.org/10.1525/cond.2013.120176 (2013).

28. Ginsberg, J. R. et al. Handling and survivorship of African wild dog (Lycaon pictus) in five ecosystems. Conserv. Biol. 9, 665-674. https://doi.org/10.1046/j.1523-1739.1995.09030665.x (1995).

29. Ponjoan, A. et al. Adverse effects of capture and handling little bustard. J. Wildl. Manag. 72, 315-319. https://doi. org/10.2193/2006-443 (2008).

30. Kukalová, M., Gazárková, A. \& Adamík, P. Should I stay or should I go? The influence of handling by researchers on den use in an arboreal nocturnal rodent. Ethology 119, 848-859. https://doi.org/10.1111/eth.12126 (2013).

31. Wingfield, J. C. \& Sapolsky, R. M. Reproduction and resistance to stress: when and how. J. Neuroendocrinol. 15, 711-724. https ://doi.org/10.1046/j.1365-2826.2003.01033.x (2003).

32. Grissom, N. \& Bhatnagar, S. Habituation to repeated stress: get used to it. Neurobiol. Learn. Mem. 92, 215-224. https://doi. org/10.1016/j.nlm.2008.07.001 (2009).

33. Lindenmayer, D. B. et al. Value of long-term ecological studies. Austral. Ecol. 37, 745-757. https://doi.org/10.111 1/j.1442-9993.2011.02351.x (2012).

34. Schell, C. J., Young, J. K., Lonsdorf, E. V., Santymire, R. M. \& Mateo, J. M. Parental habituation to human disturbance over time reduces fear of humans in coyote offspring. Ecol. Evol. 8, 12965-12980. https://doi.org/10.1002/ece3.4741 (2018).

35. Campbell, R. D., Newman, C., Macdonald, D. W. \& Rosell, F. Proximate weather patterns and spring green-up phenology effect Eurasian beaver (Castor fiber) body mass and reproductive success: the implications of climate change and topography. Global Change Biol. 19, 1311-1324. https://doi.org/10.1111/gcb.12114 (2013).

36. Campbell, R. D., Rosell, F., Newman, C. \& Macdonald, D. W. Age-related changes in somatic condition and reproduction in the Eurasian beaver: resource history influences onset of reproductive senescence. PLoS ONE 12, e0187484. https://doi.org/10.1371/ journal.pone.0187484 (2017).

37. Parker, H., Zedrosser, A. \& Rosell, F. Age-specific reproduction in relation to body size and condition in female Eurasian beavers. J. Zool. 302, 236-243. https://doi.org/10.1111/jzo.12458 (2017).

38. Sun, L. X. \& Muller-Schwarze, D. Anal gland secretion codes for relatedness in the beaver Castor canadensis. Ethology 104, 917-927. https://doi.org/10.1111/j.1439-0310.1998.tb00041.x (1998).

39. Rosell, F., Bergan, P. \& Parker, H. Scent-marking in the Eurasian beaver (Castor fiber) as a means of territory defense. J. Chem. Ecol. 24, 207-219. https://doi.org/10.1023/A:1022524223435 (1998).

40. Mayer, M., Frank, S. C., Zedrosser, A. \& Rosell, F. Causes and consequences of inverse density-dependent territorial behaviour and aggression in a monogamous mammal. J. Anim. Ecol. 89, 577-588. https://doi.org/10.1111/1365-2656.13100 (2019).

41. Hohwieler, K., Rosell, F. \& Mayer, M. Scent-marking behavior by subordinate Eurasian beavers. Ethology 124, 591-599. https:// doi.org/10.1111/eth.12762 (2018).

42. Steyaert, S. M. J. G., Zedrosser, A. \& Rosell, F. Socio-ecological features other than sex affect habitat selection in the socially obligate monogamous Eurasian beaver. Oecologia 179, 1023-1032. https://doi.org/10.1007/s00442-015-3388-1 (2015).

43. Gallant, D., Bérubé, C. H., Tremblay, E. \& Vasseur, L. An extensive study of the foraging ecology of beavers (Castor canadensis) in relation to habitat quality. Can. J. Zool. 82, 922-933. https://doi.org/10.1139/z04-067 (2004).

44. Haarberg, O. \& Rosell, F. Selective foraging on woody plant species by the Eurasian beaver (Castor fiber) in Telemark Norway. J. Zool. 270, 201-208. https://doi.org/10.1111/j.1469-7998.2006.00142.x (2006).

45. Pinto, B., Santos, M. J. \& Rosell, F. Habitat selection of the Eurasian beaver (Castor fiber) near its carrying capacity: an example from Norway. Can. J. Zool. 87, 317-325. https://doi.org/10.1139/Z09-015 (2009).

46. Sharpe, F. \& Rosell, F. Time budgets and sex differences in the Eurasian beaver. Anim. Behav. 66, 1059-1067. https://doi. org/10.1006/anbe.2003.2274 (2003).

47. Graf, P. M., Mayer, M., Zedrosser, A., Hacklander, K. \& Rosell, F. Territory size and age explain movement patterns in the Eurasian beaver. Mamm. Biol. 81, 587-594. https://doi.org/10.1016/j.mambio.2016.07.046 (2016).

48. Gallant, D. et al. Linking time budgets to habitat quality suggests that beavers (Castor canadensis) are energy maximizers. Can. J. Zool. 94, 671-676. https://doi.org/10.1139/cjz-2016-0016 (2016).

49. Graf, P. M., Hochreiter, J., Hacklander, K., Wilson, R. P. \& Rosell, F. Short-term effects of tagging on activity and movement patterns of Eurasian beavers (Castor fiber). Eur. J. Wildl. Res. 62, 725-736. https://doi.org/10.1007/s10344-016-1051-8 (2016).

50. Deguchi, T., Suryan, R. M. \& Ozaki, K. Muscle damage and behavioral consequences from prolonged handling of albatross chicks for transmitter attachment. J. Wildl. Manag. 78, 1302-1309. https://doi.org/10.1002/jwmg.765 (2014).

51. Grisham, B. A. et al. Evaluation of capture techniques on Lesser Prairie-Chicken trap injury and survival. J. Fish Wildl. Manag. 6, 318-326. https://doi.org/10.3996/032015-JFWM-022 (2015).

52. Laurenson, M. K. \& Caro, T. Monitoring the effects of non-trivial handling in free-living cheetahs. Anim. Behav. 47, 547-557. https://doi.org/10.1006/anbe.1994.1078 (1994)

53. Jakob, E. M., Marshall, S. D. \& Uetz, G. W. Estimating fitness: a comparison of body condition indices. Oikos 77, 61-67. https ://doi.org/10.2307/3545585 (1996).

54. Millar, J. S. \& Hickling, G. J. Fasting endurance and the evolution of mammalian body size. Funct. Ecol. 4, 5-12. https://doi. org/10.2307/2389646 (1990)

55. Guinet, C., Roux, J. P., Bonnet, M. \& Mison, V. Effect of body size, body mass, and body condition on reproduction of female South African fur seals (Arctocephalus pusillus) in Namibia. Can. J. Zool. 76, 1418-1424. https://doi.org/10.1139/z98-082 (1998).

56. Smith, D. W. \& Jenkins, S. H. Seasonal change in body mass and size of tail of northern beavers. J. Mammal. 78, 869-876. https ://doi.org/10.2307/1382945 (1997)

57. Magurran, A. E. \& Garcia, C. M. Sex differences in behaviour as an indirect consequence of mating system. J. Fish Biol. 57, 839-857. https://doi.org/10.1111/j.1095-8649.2000.tb02196.x (2000).

58. Drickamer, L. C., Vandenbergh, J. G. \& Colby, D. R. Predictors of dominance in the male golden hamster (Mesocricetus auratus). Anim. Behav. 21, 557-563. https://doi.org/10.1016/s0003-3472(73)80016-8 (1973).

59. Bernstein, I. S. Dominance: the baby and the bathwater. Behav. Brain Sci. 4, 419-429. https://doi.org/10.1017/S0140525X000096 $14(1981)$.

60. Taillon, J. \& Côté, S. D. The role of previous social encounters and body mass in determining social rank: an experiment with white-tailed deer. Anim. Behav. 72, 1103-1110. https://doi.org/10.1016/j.anbehav.2006.03.016 (2006).

61. Marolf, B., McElligott, A. G. \& Müller, A. E. Female social dominance in two Eulemur species with different social organizations. Zoo. Biol. 26, 201-214. https://doi.org/10.1002/zoo.20135 (2007).

62. Huang, B., Wey, T. W. \& Blumstein, D. T. Correlates and consequences of dominance in a social rodent. Ethology 117, 573-585 (2011).

63. Righton, D., Miller, M. \& Ormond, R. Correlates of territory size in the butterflyfish Chaetodon austriacus (Rüppell). J. Exp. Mar. Biol. Ecol. 226, 183-193. https://doi.org/10.1016/s0022-0981(97)00235-9 (1998).

64. Bobek, B. Summer food as the factor limiting roe deer population size. Nature 268, 47. https://doi.org/10.1038/268047a0 (1977).

65. Myers, J. P., Connors, P. G. \& Pitelka, F. A. Territory size in wintering sanderlings: the effects of prey abundance and intruder density. Auk 96, 551-561. https://doi.org/10.1093/auk/96.3.551 (1979).

66. Gass, C. L., Angehr, G. \& Centa, J. Regulation of food supply by feeding territoriality in the rufous hummingbird. Can. J. Zool. 54, 2046-2054. https://doi.org/10.1139/z76-238 (1976). 
67. Adams, E. S. Approaches to the study of territory size and shape. Annu. Rev. Ecol. Syst. 32, 277-303. https://doi.org/10.1146/ annurev.ecolsys.32.081501.114034 (2001).

68. Kelly, K. G., Diamond, A. W., Holberton, R. L. \& Bowser, A. K. Researcher handling of incubating Atlantic Puffins Fratercula arctica has no effect on reproductive success. Mar. Ornithol. 43, 77-82 (2015).

69. Ramsay, M. A. \& Stirling, I. Long-term effects of drugging and handling free-ranging polar bears. J. Wildl. Manag. 1, 619-626. https://doi.org/10.2307/3800972 (1986).

70. Serventy, D. L. \& Curry, P. J. Observations on colony size, breeding success, recruitment and inter-colony dispersal in a Tasmanian colony of Short-tailed Shearwaters Puffinus tenuirostris over a 30-year peroid. EMU 84, 71-79. https://doi.org/10.1071/MU984 $0071(1984)$

71. Schradin, C. \& Hayes, L. D. A synopsis of long-term field studies of mammals: achievements, future directions, and some advice. J. Mammal. 98, 670-677. https://doi.org/10.1093/jmammal/gyx031 (2017).

72. Blumstein, D. T. Habituation and sensitization: new thoughts about old ideas. Anim. Behav. 120, 255-262. https://doi. org/10.1016/j.anbehav.2016.05.012 (2016).

73. Baudains, T. P. \& Lloyd, P. Habituation and habitat changes can moderate the impacts of human disturbance on shorebird breeding performance. Anim. Conserv. 10, 400-407. https://doi.org/10.1111/j.1469-1795.2007.00126.x (2007).

74. Vincze, E. et al. Habituation to human disturbance is faster in urban than rural house sparrows. Behav. Ecol. 27, 1304-1313. https://doi.org/10.1093/beheco/arw047 (2016).

75. Van Oers, K. \& Carere, C. Long-term effects of repeated handling and bleeding in wild caught great tits Parus major. J. Ornithol. 148, 185-190. https://doi.org/10.1007/s10336-007-0200-y (2007).

76. Ordiz, A. et al. Habituation, sensitization, or consistent behavioral responses? Brown bear responses after repeated approaches by humans on foot. Biol. Conserv. 232, 228-237. https://doi.org/10.1016/j.biocon.2019.01.016 (2019).

77. Seress, G. et al. Effects of capture and video-recording on the behavior and breeding success of Great Tits in urban and forest habitats. J. Field Ornithol. 88, 299-312. https://doi.org/10.1111/jofo.12205 (2017).

78. Ellenberg, U., Mattern, T., Houston, D. M., Davis, L. S. \& Seddon, P. J. Previous experiences with humans affect responses of Snares Penguins to experimental disturbance. J. Ornithol. 153, 621-631. https://doi.org/10.1007/s10336-011-0780-4 (2012).

79. Ditmer, M. A. et al. Bears habituate to the repeated exposure of a novel stimulus, unmanned aircraft systems. Conserv. Physiol. 7, 67. https://doi.org/10.1093/conphys/coy067 (2019).

80. Rabdeau, J., Badenhausser, I., Moreau, J., Bretagnolle, V. \& Monceau, K. To change or not to change experimenters: caveats for repeated behavioural and physiological measures in Montagu's harrier. J. Avian Biol. 50, 1. https://doi.org/10.1111/jav.02160 (2019).

81. Rode, K. D. et al. Effects of capturing and collaring on polar bears: findings from long-term research on the southern Beaufort Sea population. Wildl. Res. 41, 311-322. https://doi.org/10.1071/WR13225 (2014).

82. Larsen, K. W. \& Boutin, S. Movements, survival, and settlement of red squirrel (Tamiasciurus hudsonicus) offspring. Ecology 75, 214-223. https://doi.org/10.2307/1939395 (1994).

83. Mayer, M., Zedrosser, A. \& Rosell, F. Couch potatoes do better: Delayed dispersal and territory size affect the duration of territory occupancy in a monogamous mammal. Ecol. Evol. 7, 4347-4356. https://doi.org/10.1002/ece3.2988 (2017).

84. Mayer, M., Zedrosser, A. \& Rosell, F. Extra-territorial movements differ between territory holders and subordinates in a large, monogamous rodent. Sci. Rep. 7, 15261. https://doi.org/10.1038/s41598-017-15540-0 (2017).

85. Rosell, F., Johansen, G. \& Parker, H. Eurasian beavers (Castor fiber) behavioral response to simulated territorial intruders. Can. J. Zool. 78, 931-935. https://doi.org/10.1139/cjz-78-6-931 (2000).

86. Rosell, F. \& Bjorkoyli, T. A test of the dear enemy phenomenon in the Eurasian beaver. Anim. Behav. 63, 1073-1078. https://doi. org/10.1006/anbe.2002.3010 (2002).

87. Tinnesand, H. V., Jojola, S., Zedrosser, A. \& Rosell, F. The smell of desperadoes? Beavers distinguish between dominant and subordinate intruders. Behav. Ecol. Sociobiol. 67, 895-904. https://doi.org/10.1007/s00265-013-1512-y (2013).

88. Fretwell, S. D. Populations in a seasonal environment. (Princeton University Press, 1972).

89. Rosell, F., Parker, H. \& Steifetten, O. Use of dawn and dusk sight observations to determine colony size and family composition in Eurasian beaver Castor fiber. Acta Theriol. 51, 107-112. https://doi.org/10.1007/Bf03192662 (2006).

90. Shier, D. M. \& Swaisgood, R. R. Fitness costs of neighborhood disruption in translocations of a solitary mammal. Conserv. Biol. 26, 116-123. https://doi.org/10.1111/j.1523-1739.2011.01748.x (2012).

91. Shier, D. M. Effect of family support on the success of translocated black-tailed prairie dogs. Conserv. Biol. 20, 1780-1790. https ://doi.org/10.1111/j.1523-1739.2006.00512.x (2006).

92. Gaillard, J. M., Allainé, D., Pontier, D., Yoccoz, N. G. \& Promislow, D. E. L. Senescence in natural populations of mammals: a reanalysis. Evolution 48, 509-516. https://doi.org/10.1111/j.1558-5646.1994.tb01329.x (1994).

93. Lindenmayer, D. B. \& Likens, G. E. Adaptive monitoring: a new paradigm for long-term research and monitoring. Trends Ecol. Evol. 24, 482-486. https://doi.org/10.1016/j.tree.2009.03.005 (2009).

94. Campbell, R. D., Rosell, F., Nolet, B. A. \& Dijkstra, V. A. A. Territory and group sizes in Eurasian beavers (Castor fiber): echoes of settlement and reproduction?. Behav. Ecol. Sociobiol. 58, 597-607. https://doi.org/10.1007/s00265-005-0942-6 (2005).

95. Sun, L., Müller-Schwarze, D. \& Schulte, B. A. Dispersal pattern and effective population size of the beaver. Can. J. Zool. 78, 393-398. https://doi.org/10.1139/z99-226 (2000).

96. Campbell, R. D., Nouvellet, P., Newman, C., Macdonald, D. W. \& Rosell, F. The influence of mean climate trends and climate variance on beaver survival and recruitment dynamics. Global Change Biol. 18, 2730-2742. https://doi.org/10.111 $1 / j .1365-2486.2012 .02739 . x(2012)$.

97. Rosell, F. \& Hovde, B. Methods of aquatic and terrestrial netting to capture Eurasian beavers. Wildl. Soc. Bull. 29, 269-274 (2001).

98. Rosell, F. \& Sun, L. Use of anal gland secretion to distinguish the two beaver species Castor canadensis and C. fiber. Wildl. Biol. 5, 119-123. https://doi.org/10.2981/wlb.1999.015 (1999).

99. Rosell, F., Zedrosser, A. \& Parker, H. Correlates of body measurements and age in Eurasian beaver from Norway. Eur. J. Wildl. Res. 56, 43-48. https://doi.org/10.1007/s10344-009-0289-9 (2010).

100. Mayer, M., Künzel, F., Zedrosser, A. \& Rosell, F. The 7-year itch: non-adaptive mate change in the Eurasian beaver. Behav. Ecol. Sociobiol. 71, 1. https://doi.org/10.1007/s00265-016-2259-z (2017).

101. Buchanan, K. et al. Guidelines for the treatment of animals in behavioural research and teaching. Anim. Behav. 83, 301-309. https://doi.org/10.1016/j.anbehav.2011.10.031 (2012).

102. Aleksiuk, M. The function of the tail as a fat storage depot in the beaver (Castor canadensis). J. Mammal. 51, 145-148. https:// doi.org/10.2307/1378541 (1970).

103. Parker, H., Rosell, F. \& Mysterud, A. Harvesting of males delays female breeding in a socially monogamous mammal; the beaver. Biol. Lett. 3, 107-109. https://doi.org/10.1098/rsbl.2006.0563 (2007).

104. Fouchet, D., Santin-Janin, H., Sauvage, F., Yoccoz, N. G. \& Pontier, D. An R package for analysing survival using continuous-time open capture-recapture models. Methods Ecol. Evol. 7, 518-528. https://doi.org/10.1111/2041-210x.12497 (2016).

105. Borchers, D., Distiller, G., Foster, R., Harmsen, B. \& Milazzo, L. Continuous-time spatially explicit capture-recapture models, with an application to a jaguar camera-trap survey. Methods Ecol. Evol. 5, 656-665. https://doi.org/10.1111/2041-210X.12196 (2014). 
106. Lebreton, J.-D., Burnham, K. P., Clobert, J. \& Anderson, D. R. Modeling survival and testing biological hypotheses using marked animals: a unified approach with case studies. Ecol. Monogr. 62, 67-118. https://doi.org/10.2307/2937171 (1992).

107. Bonnet, X., Naulleau, G. \& Shine, R. The dangers of leaving home: dispersal and mortality in snakes. Biol. Conserv. 89, 39-50. https://doi.org/10.1016/S0006-3207(98)00140-2 (1999).

108. Lucas, J. R., Waser, P. M. \& Creel, S. R. Death and disappearance: estimating mortality risks associated with philopatry and dispersal. Behav. Ecol. 5, 135-141. https://doi.org/10.1093/beheco/5.2.135 (1994).

109. Zuur, A. F., Ieno, E. N., Walker, N. J., Saveliev, A. A. \& Smith, G. M. Mixed effects models and extensions in ecology with R. (Springer, Berlin, 2009).

110. Burnham, K. P. \& Anderson, D. R. Model selection and multimodel inference: a practical information-theoretic approach. (Springer, Berlin, 2002).

111. Magnusson, A. et al. Package 'glmmTMB'. R Package (2017).

112. Barton, K. R-package 'MuMIn' (2018).

113. Arnold, T. W. Uninformative parameters and model selection using Akaike's information criterion. J. Wildl. Manage 74, 11751178. https://doi.org/10.1111/j.1937-2817.2010.tb01236.x (2010).

114. Hartig, F. DHARMa: residual diagnostics for hierarchical (multi-level/mixed) regression models. $R$ package (2017).

115. Team, R. C. R: A Language and Environment for Statistical Computing, R Foundation for Statistical Computing, Austria, 2015. (2018).

\section{Acknowledgements}

This study was founded by the University of South-Eastern Norway. We thank everyone who over the years have contributed to the field work within the NBP. We thank S. Farrell who did a preliminary study on long-term capture effects on the body condition in Eurasian beavers. Thanks to R. Morrison Svensson and R. Hinds who reviewed the language of our paper. We thank three anonymous reviewers and the editor for their constructive comments that improved our manuscript.

\section{Author contributions}

F.R. founded the NBP, F.R. and R.M.M. contributed to the data collection, R.M.M. performed the statistical analyses, R.M.M. and F.R. wrote the manuscript.

\section{Competing interests}

The authors declare no competing interests.

\section{Additional information}

Supplementary information is available for this paper at https://doi.org/10.1038/s41598-020-74933-w.

Correspondence and requests for materials should be addressed to R.M.M.

Reprints and permissions information is available at www.nature.com/reprints.

Publisher's note Springer Nature remains neutral with regard to jurisdictional claims in published maps and institutional affiliations.

(c) (i) Open Access This article is licensed under a Creative Commons Attribution 4.0 International

License, which permits use, sharing, adaptation, distribution and reproduction in any medium or format, as long as you give appropriate credit to the original author(s) and the source, provide a link to the Creative Commons licence, and indicate if changes were made. The images or other third party material in this article are included in the article's Creative Commons licence, unless indicated otherwise in a credit line to the material. If material is not included in the article's Creative Commons licence and your intended use is not permitted by statutory regulation or exceeds the permitted use, you will need to obtain permission directly from the copyright holder. To view a copy of this licence, visit http://creativecommons.org/licenses/by/4.0/.

(c) The Author(s) 2020 